Review

\title{
Monitoring of transport infrastructure exposed to multiple hazards: a roadmap for building resilience
}

\author{
Dimitra V. Achillopoulou URL: http://www.infrastructuresilience.com ${ }^{\mathrm{a}, \mathrm{b}},{ }^{*}$, Stergios A. Mitoulis $^{\mathrm{a}}$, \\ Sotirios A. Argyroudis ${ }^{\mathrm{a}, \mathrm{c}}$, Ying Wang ${ }^{\mathrm{a}, \mathrm{d}}$ \\ a Department of Civil and Environmental Engineering, University of Surrey, UK. \\ ${ }^{\mathrm{b}}$ Department of Civil Engineering, Democritus University of Thrace, Greece \\ c Department of Civil Engineering, Aristotle University of Thessaloniki, Greece \\ ${ }^{\mathrm{d}}$ School of Civil and Environmental Engineering, Harbin Institute of Technology (Shenzhen), Shenzhen, China
}

\section{A R T I CLE IN F O}

\section{Article history:}

Received 27 March 2020

Received in revised form 6 July 2020

Accepted 14 July 2020

Available online $\mathrm{xxx}$

Editor: Deyi Hou

\begin{abstract}
A B S T R A C T
Monitoring-enhanced resilience in transport management is emerging together with the new technologies and digital data, however have not been fully explored yet. Digital technologies have the potential to provide rapid resilience assessments in a quantifiable and engineered manner for transport infrastructure, which is exposed to multiple natural and human-induced hazards and diverse loads throughout their life-cycle. Physical damage and disruption of networks and interdependent systems may cause tremendous socioeconomic impact, affecting world economies and societies. Nowadays, transport infrastructure stakeholders have shifted the requirements in risk and resilience assessment. The expectation is that risk is estimated efficiently, almost in real-time with high accuracy, aiming at maximising the functionality and minimising losses. Nevertheless, no integrated framework exists for quantifying resilience to diverse hazards, based on structural and functionality monitoring (SHFM) data, and this is the main capability gap that this paper envisages filling. Monitoring systems have been used widely in transport infrastructure and have been studied extensively in the literature. Data can facilitate prognosis of the asset condition and the functionality of the network, informing computer-based asset and traffic models, which can assist in defining actionable performance indicators, for diagnosis and for defining risk and loss expediently and accurately. Evidence exists that SHFM is an enabler of resilience. However, strategies are absent in support of monitoring-based resilience assessment in transport infrastructure management. In response to the above challenge, this paper puts forward for the first time in the international literature, a roadmap for monitoring-based quantification of resilience for transport infrastructure, based on a comprehensive review of the current state-of-the-art. It is a holistic asset management roadmap, which identifies the interactions among the design, monitoring, risk assessment and quantification of resilience to multiple hazards. Monitoring is embraced as a vital component, providing expedient feedback for recovery measures, accelerating decision-making for adaptation of changing ecosystems and built environments, utilising emerging technologies, to continuously deliver safer and resilient transport infrastructure.

\section{Introduction}

With the beginning of the 21st century, the digital revolution has underpinned most of the human activities (Sachs et al., 2019). It has the potential to deliver not only advanced communications but also groundbreaking digital solutions in critical infrastructure to ensure safety and resilience (Lloyd's Register Foundation, 2015). The latter

\footnotetext{
* Corresponding author at: Dept. of Civil and Environmental Engineering, University of Surrey, UK.

E-mail address: d.achillopoulou@surrey.ac.uk (D.V. Achillopoulou)
}

means enhancing the ability to anticipate, prepare for, and adapt to changing conditions and withstand, respond to, and recover rapidly from disruptions (FHWA, 2014). The international literature has not exploited yet digital technologies for quantifying resilience to multiple hazards. The objective of this paper is to deliver a roadmap toward resilience for transport infrastructure exposed to multiple hazards throughout their life-cycle (Argyroudis et al., 2019, 2020), including the: (i) accumulation of damage due to human-induced stressors and/ or sequences of events, which can be independent or cascading in nature, and potential exacerbation due to environmental and climate deviations (Zscheischler et al., 2018), and (ii) abrupt disruptions after extreme hazards, not precluding that accumulation (i) might precede the hazard event (ii). In this respect, the resilience of transport in- 
frastructure is of paramount importance to world economies and societies (Woetzel et al., 2020) and contributes toward the UNs Sustainable Development Goals (SDG), which heavily relying upon the integrity of the assets and the functionality of the networks (United Nations General Assembly, 2015). Hence, transport infrastructure urgently needs adaptation and therefor build climate resilience that is the versatility to increasing impacts and demands (Linkov et al., 2014), whilst emerging technologies and digital innovation can significantly facilitate this goal.

The investment requirements toward this resilience transformation are very high. It reaches on average $€ 688$ billion per year for maintenance (EIB) of the existing European economic infrastructure that is the energy, transport, water and sanitation, and telecoms (Zachariadis, 2018 ) and $€ 20$ billion for transport infrastructure and their losses due to natural hazards (European Union Road Federation, 2017; Hallegatte et al., 2019). The expected expenditure is similar in the USA and Asia. The Transportation Research Board's (TRB) recent meetings have emphasized the significance of transport infrastructure resilience to natural hazards and climate change effects (Stamos et al., 2015; Dowds and Aultman-Hall, 2015; Schweikert et al., 2015). The American Society of Civil Engineers estimates that neglecting to act toward preserving a healthy transportation system, will have a tremendous impact on business productivity, gross domestic product (GDP), employment, personal impact and competitiveness (World Economic Forum, 2014 ). In monetary terms, approximately $\$ 3.9$ trillion in losses, $\$ 7$ trillion in lost business sales and 2.5 million loss of jobs are expected by 2025 (ASCE, 2017). The Asian Development Bank forecasts that Asia needs to invest $\$ 1.5$ trillion a year in infrastructure from 2016 until 2030 to keep pace with economic growth. This is expected to be increased by $16 \%$ due to climate change, excluding mitigation and adaptation measures (ADB, 2017). The continuous need to extend the life of transport assets (International Transport Forum, 2018) and to upgrade their capacity is associated with the increasing traffic loads (Havaei-Ahary, 2018), as well as the environmental and human-induced hazards (Dong et al. 2013; Kaundinya et al., 2016; Vamvakeridou-Lyroudia et al., 2020). Natural hazards were proved to be exacerbated due to climate change in an ever-changing environment (Pant et al., 2018; Forzieri et al., 2018; Sarkodie and Strezov, 2019) imposing adaptation measures to build resilience (Nasr et al., 2019; Renne et al., 2019).

The uncertainties in defining transport asset condition response, properties and loads, during their life-cycle can be reduced by monitoring the structural integrity with measurements that directly estimate the loss of the capacity and functionality (FHWA, 2013; Winter, 2014; Highways England, 2016a, 2016b; Dawson et al., 2016; NCHRP, 2018) estimating indirectly the resistance and robustness of the network. Hence, the challenge in assessing and managing transport infrastructure is associated with the vulnerabilities of the assets, combined with the changeability of climatic and other hazards.

Furthermore, it is widely recognized that Quantitative Risk Analysis (QRA) is important, for the resilience assessment and adaptability of critical transport assets (UNDRR, 2011; FHWA, 2013). QRA assists in estimating the potential economic, functional and social losses, determined probabilistically, as a function of hazard, exposure and vulnerability (UNISDR, 2009), including the associated uncertainties. More recently, quantitative resilience assessment frameworks have been proposed for transport infrastructure exposed to multiple hazards and extreme events (Ayyub, 2014; Yang and Frangopol, 2018; Argyroudis et al., 2020), which are inclusive of the asset vulnerability and the rapidity of post-event recovery, as described in Section 2 below.

The novelty of this paper is that it provides the link between the components of multiple hazard resilience assessment in transport infrastructure based on a variety of Structural Health and Functionality Monitoring (SHFM) data, and their fusion with models for delivering actionable performance indicators and diagnosis. Breaking that down into the components of risk and resilience this study discusses extensively setting a roadmap on how SHFM data, can provide rapid and reliable measurands of exposure, hazard, vulnerability for the response, recovery and adaptation (Galaitsi et al., 2019). This holistic approach in asset management fits squarely into the current vision for delivering resilient-based design and assessment of transport infrastructure (Almufti and Willford, 2013; Linkov et al., 2014; Li et al., 2017; NCHRP, 2018; Guthrie et al., 2019; Reeves et al., 2019).

The paper is divided into five sections. Section 2 describes how SHFM can enhance resilience in component, asset and system-level, both for cumulative and abrupt events, in a holistic mannerAlso, this section describes how monitoring can enhance the agility and how this improves in a quantifiable manner the resilience. Section 3 contains an extensive review of available heterogeneous analogue or digital SHFM systems in transport infrastructure, which are classified based on (i) the nature of the measurand, (ii) their type, (iii) their function principle, (iv) their contribution in risk and resilience assessment and (v) cost. Section 4 describes the model updating procedure based on monitoring feedback achieving accurate and reliable predictions of the performance. Section 5 provides insights on how individual components of risk and resilience can be benefited, by improving their accuracy, reliability and rapidity based on SHFM data in the analysis of complex networks (Linkov et al., 2018). The paper concludes with urgent needs in monitoring-based management of critical transport infrastructure toward resilience and adaptation.

\section{Roadmap to monitoring-enhanced resilience management of transport infrastructure}

The ability of transport networks to adapt to increased loads and natural and human-induced hazard is dependent on their capacity, redundancy and on the ecosystem, in which they reside. Inherently, it also depends on the condition and life-cycle of assets, the owners' resources for maintenance, monitoring, restoration and adaptation (Zhu and Frangopol, 2012; Argyroudis et al., 2020). Throughout the life-cycle of the transport network, resilience may vary due to the complexities and interdependencies (Dong and Frangopol, 2016; Franchin, 2018; Liu et al., 2019) within the network and the impacts of multiple hazards (Frangopol and Bocchini, 2011; ; Yang and Frangopol 2018; Xian et al., 2018).

Infrastructure resilience has received a lot of attention in recent years (; ; Ayyub, 2014; Linkov et al., 2014; Linkov and Trump, 2019; Reeves et al., 2019). What has been agreed in these studies is that the uncertainties of all engineering processes, involved in the estimation of resilience 0 is complicated and is causing strong implications for the management of networks and their adaptation to an ever-changing environment (Cimellaro et al. 2016). Thus, monitoring using digital technologies, that reduce the uncertainty in resilience evaluation, is of paramount importance for building climate-resilience in the near future.

\subsection{Use of monitoring data for enhancing resilience}

The resilience of the network is a function of the resilience of its hard assets, e.g. bridges, tunnels, embankments, road pavement, rail tracks, junctions and hubs. Additionally, resilience is dependent on the response of the structural components of which assets comprise, e.g. foundations, slabs, beams, columns, deck, plates, piers, tunnel linings. In this research, soft assets, ssuch as policies, regulations, procedures have not been included within the roadmap, as this is beyond the scope of this paper, yet it is recognised that there are strong interdependencies between hard and soft assets, influencing the resilience of the transport infrastructure network, as a whole. 


\subsubsection{Resilience quantification}

Fig. 1 illustrates the resilience over time for components (Fig. 1 a \& b), e.g. beams, columns, slabs, assets (Fig. 1 b \& e), e.g. bridges, tunnels, retaining walls, and networks (Fig. 1c \& f), e.g. highways and railways for cumulative and abrupt hazard events. The resilience is measured based on different performance indicators that are the capacity for structural component and capacity or functionality for the assets and networks. The fluctuation of resilience is illustrated over time, from the completion of the construction $\left(t_{0}\right)$, to the end of its design lifetime ( ) or to the extended life-cycle $\left(\boldsymbol{t}_{\text {end }}{ }^{\text {ext }}\right)$. Fig. $1 \mathrm{a}, \mathrm{b} \& \mathrm{c}$ show the resilience curves for cumulative damage, while Fig. 1d, e \& f illustrate the case of extreme hazards, which are abrupt and the loss of capacity/functionality is sudden.

Cumulative damage could be the result of ageing, exposure of the infrastructure to adverse environmental conditions or fatigue. Abrupt loss of capacity or functionality can be the aftermath of catastrophic natural and human-induced hazards, such as a (wild)fire. It is noted that the loss of functionality of a transport network under normal circumstances (Fig. 1c), e.g. accumulation of damage due to environmental stressors, cannot be substantial, e.g. below the critical functionality level $f_{\text {critical }}$ as failures are unlikely to occur simultaneously within the same network. However, this is not the case for networks under extreme conditions, e.g. extensive flash floods, where a number of assets might fail, and hence, the functionality of the network can be abruptly and unexpectedly reduced below the critical one.

The black solid lines in Fig. 1 illustrate the conventional approach, where only traditional inspections are performed periodically. The red plots illustrate the enhanced resilience models as a result of the deployment of monitoring systems (M). Each segment of the resilience curves is accompanied by the corresponding uncertainty, with an indicative probability density function (PDF). The capacity and functionality of components at the beginning of the life-cycle of assets and networks is equal to 1 which is the theoretical design performance. There are different distinct periods at the life-cycle i.e. 1: normal function, 2: accumulation of damage, 3: mitigation measures, 4: bounce back to normal function/adaptation and potentially life extension. Based on the literature (Mattsson and Jenelius, 2015; Ganin et al., 2017; Linkov et al., 2018), monitoring has the potential to influence the aforementioned periods by (a) compressing the post-damage response time, i.e. $t_{\text {resp }}{ }^{M}<t_{\text {resp }}{ }^{N M}$, and by reducing the lag time in the strategic planning for decision-making $\left(\boldsymbol{t}_{\text {resp }}-\boldsymbol{t}_{\text {strat }}{ }^{\text {pla }}\right)$ or the idle time that is the period of no or limited use of the asset or network, (b) helping to recover faster, $t_{\text {rec }}{ }^{M}<t_{\text {rec }}$ due to prognosis, i.e. better and expedient understanding of the infrastructure condition, (c) increasing the reliability of the data, (d) permitting recovery to initiate from a level higher than the residual capacity $\left(c_{\text {resp }}{ }^{M}>c_{\text {residual }}\right)$ and fully regain the performance level, and (e) enabling timely decision-making and recovery, prior to infrastructure reaches its critical functionality or capacity $c_{\text {critical }}$ i.e. $c_{\text {resp }}{ }^{M}>c_{\text {residual }}$. Hence, monitoring enables continuous and expedient adaptation to new demands, e.g. climate change $\left(t_{\text {adapt }}^{M i}<t_{\text {rec }}^{p-M}<t_{\text {adapt }}^{N M i}\right)$.

The resilience is commonly quantified with a resilience index $R$, see Eqs. (1) and (2), which is a function of the time-variant functionality of the infrastructure over time, for the given hazard or stressor (Frangopol and Bocchini, 2011; Ayyub, 2014). The resilience index of an asset is given by the following equations when the investigated time horizon is the time of adaptation $\boldsymbol{t}_{\text {adapt }}$ and $\boldsymbol{t}_{\text {adapt }}{ }^{\boldsymbol{M}}$ after applying mitigation measures, for the cases where no monitoring (Eq. (1)) or enhanced monitoring is used (Eq. (2)):

$\mathrm{R}=\frac{1}{\mathrm{t}_{\text {adapt }}-\mathrm{t}_{0}} \int_{\mathrm{t}_{0}}^{\mathrm{t}_{\text {adapt }}} \mathrm{Q}(\mathrm{t}) \mathrm{dt}$
$\mathrm{R}^{\mathrm{M}}=\frac{1}{\mathrm{t}_{\text {adapt }}^{\mathrm{M}}-\mathrm{t}_{0}} \int_{\mathrm{t}_{0}}^{\mathrm{t}_{\text {adapt }}^{\mathrm{M}}} \mathrm{Q}(\mathrm{t}) \mathrm{dt}$

where $Q(t)$ is the functionality of the asset over time, (see Fig. 1g: Nomenclature). Based on the above, resilience with monitoring is greater than without monitoring $\left(\mathrm{R}^{\mathrm{M}}>\mathrm{R}\right)$. It is noted that the time horizon might be different, e.g. $\boldsymbol{t}_{\text {end }}$ or $\boldsymbol{t}_{\text {end }}$ ext $^{\text {depending on the time window }}$ for which resilience is quantified.

\subsubsection{Monitoring-enhanced resilience}

Monitoring systems can also provide timely early warnings (Fabozzi et al., 2018; Bindi et al., 2015) early after the initiation of the infrastructure deterioration, i.e. $t_{\text {resp }}{ }^{M}$ due to the accumulation of damage or after the loss of capacity following an extreme event at $t_{d a m}{ }^{I}$. This option provides the opportunity to achieve extended adaptation (green dashed line after the red-dashed line, $t_{\text {adapt }} t^{p-M}<t_{\text {adapt }}$ ). The early warnings for a number of assets underperforming, e.g. due to loss of capacity or functionality, can provide performance indicators and criteria for the owners/stakeholders to decide and take action should the loss is unacceptable for the network (periods M3, NM3 in Fig. 1c \& f). The decision may include deployment of restoration measures, or limiting the network operability by continuing only important services, e.g. emergency access to energy networks or airports and underpin the economic activity. Early warnings can also be translated into written warnings to end-users, and/ or with variable/dynamic signs along the network area affected.

Fig. 1 a to $f$ describes the evolution of the capacity/functionality of the asset or network throughout their lives. The threshold shown in Fig. 1a (star symbol) illustrates the case where thresholds have been exceeded and measures have to be taken. At the time instance $t_{\text {resp }}{ }^{M}$ the red line is above the black one, which means that the monitored systems are expected to give feedback for better understanding of the capacity/functionality and hence, the estimated resilience is greater when monitoring is embraced, if compared to the case where no monitoring is deployed. If monitoring is performed and early warnings are triggered, immediate measures can be taken after $t_{\text {resp }}{ }^{M}$. Contrary to the case where the conditions of the component, the asset or the network are unknown, early warnings can improve reaction time and therefore assist in mitigating the continuous degradation below the critical level ( $\left.c / f_{\text {critical }}\right)$.

Even if monitoring is deployed as an urgent post-event measure, it can improve the resilience assessment and understanding of the asset/ network condition, as shown with the red dashed line, and thus facilitating a swift bounce back to the pre-event performance level. When monitoring is deployed after, this will improve the resilience (red dashed line) and at a later time, ideally, will achieve the level of functionality of the asset/network on which monitoring is already used (red line). For example, a common practice of post-hazard installation of monitoring for cumulative damage is the cathodic protection of reinforcement steel bars with sacrificial anodes (Lambert et al., 2015) to monitor the corrosion rate of the steel bars. The impressed current cathodic protection (ICCP) systems follow the propagation of corrosion of the steel bars by monitoring the current flow and voltage, helping to define more accurately the reinforcement ratio loss due to corrosion. This evidence can aid in both mitigating the corrosion and facilitate model updating or more reliable estimations of the capacity of the structural member and enable decisions for appropriate measures during recovery.

The ultimate goal of the resilience-based management of the network is mainly the ability of the transport network to adapt to increasing demands, e.g. due to climate change, (green line in Figures 1 a to f). For instance, if the initial demand of 10,000 vehicles per day is being met, this means that the resilience of the network is equal to one. 

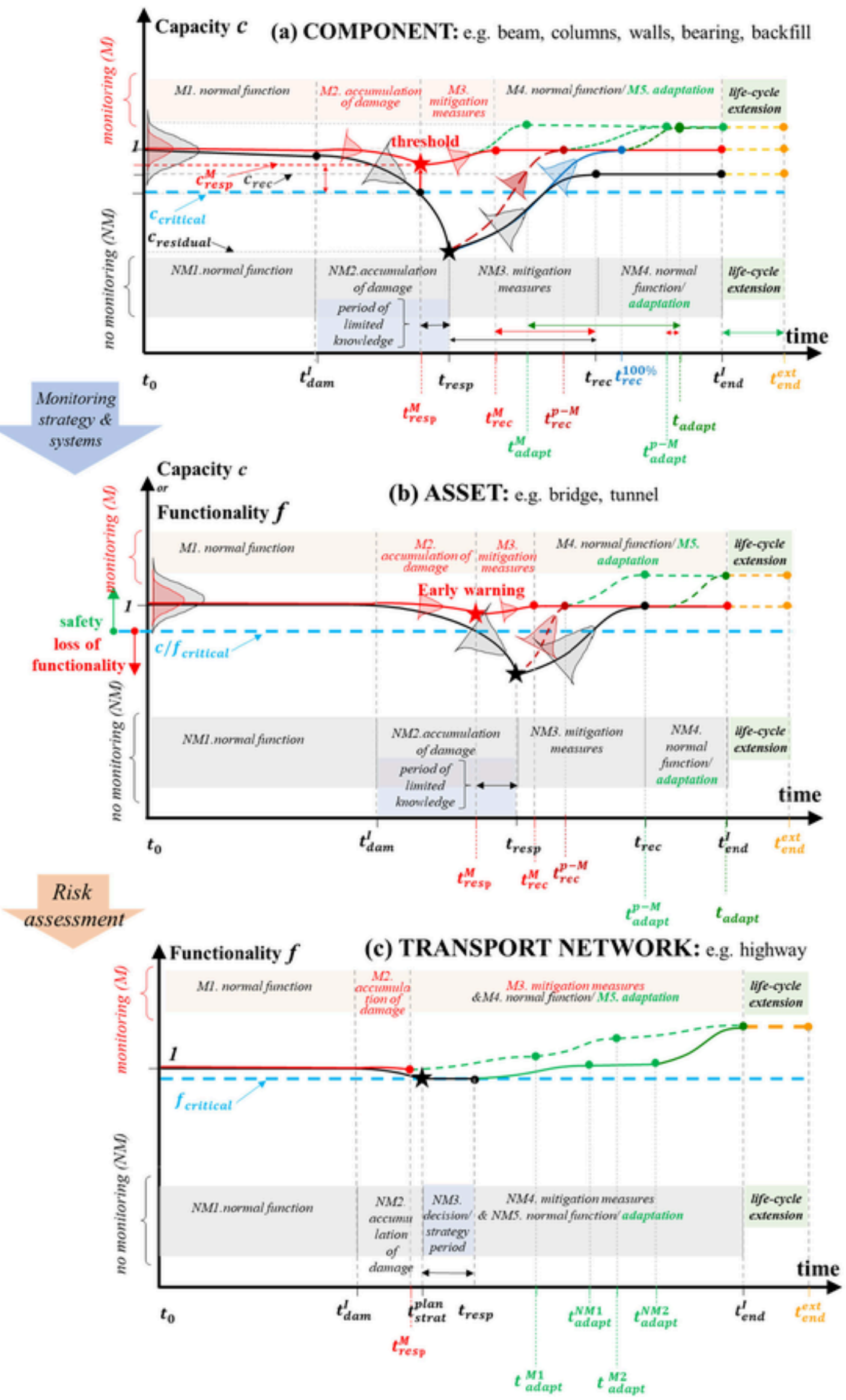
However, if this demand increases, indirectly the resilience of the entire network will be reduced. Hence, pushing the threshold of the demands upwards leads in increased requirements for adaptation to achieve the same level of resilience. To meet this requirement, the asset and/or network require restoration, in the form of updates, improvements, upgrades and continuous adaptation that can take place along the periods NM2 onwards. Analogously to cumulative damage, Fig. 1 d-f show the resilience model for extreme events based on the same rationale.

\subsection{Holistic infrastructure management for enhanced resilience}

Fig. 2 encapsulates the roadmap for building resilience to transport infrastructure. The four components of this holistic (Grasso and Burkins, 2010), resilience-based management take into consideration both local and global scale of individual parts (components and assets) as well as the network as a whole. The first component is the engineering, e.g. the structural part (grey circle), which contains the design, construction, application, loads, events, properties, geometry and exposure. The second component is the monitoring part (blue circle), e.g. the structural health, functionality, and monitoring of the ecosystem, including visualisation, inspection, quantification, characterisation and damage detection. The risk and management component follows (red circle), quantifying and describing the risk analysis, the quantification of the associated losses, to facilitate future predictions enabling model-updating for well-documented and objective decision-making and planning. In this step, the communication of risk to end-users is also included, and this is mainly the responsibility of infrastructure owners and operators. The last step of this holistic approach is shown with the external circle, which illustrates the delivery of resilience with optimised services and adaptation toward economic growth, accounting for any limitations in resources (green circle). The arrows between the homocentric circles indicate a dynamic and continuous dataflow among the components of the approach.

In the flowchart of Fig. 3, the roadmap for delivering resilience in life-cycle of critical infrastructure aided by monitoring systems is fully described with all the sub-procedures noted with different colours. The roadmap includes the hazards, which may be any natural or human-induced stressors, the exposure that is the infrastructure assets, networks or non-engineering exposure such as businesses, services and mobility, the interactions with the affected end-users and environment, and the adaptation to these interactions and hazards. Subsequently, the roadmap describes all cyclic sub-procedures and activities. In this logical process, the infrastructure is designed, delivered, monitored and assessed, taking into consideration stressors (upper grey box), in an effort to perform monitoring-based infrastructure management (middle blue box). By lowering risks and delivering undisrupted mobility, investments and/or resource allocation are optimised. Also, maximising the resilience of the network, results in robust economies, safeguards user mobility and leads to a more efficient environment (lower green box). The sub-procedures/activities that are illustrated in the flowchart follow the colours and therefore the categories of the holistic approach described above (Fig. 2). The categories include grey colours for structural activities, blue boxes for monitoring activities, orange and red for risk assessment \& management and resilience means and attributes, while green boxes indicate means for delivering sustainable and resilient infrastructure.

Transport infrastructure is expected to operate in normal circumstances, but is also expected to withstand stressors when exposed to various, multiple natural and/or human-induced hazards and extreme events. Throughout its lifecycle, after the completion of construction, infrastructure interacts with the environment, comprising together with the natural environment, an ecosystem (Argyroudis et al., 2019), whilst also influences the adjacent built environment, e.g. energy, utility, urban and other transport networks (Romero-Lankao et al., 2018; Markolf et al., 2018). Fig. 3 shows the normal design phase, during which the external stressors due to interactions, are taken into consideration. During the structural activities, the type of asset, its geometry, the materials and the properties are selected considering the expected performance and the exposure, typically by meeting the design criteria perscribed in design guidelines (e.g. EN 1998-2, 2005; AASHTO, 2017). After the construction, a monitoring strategy might be decided and deployed on the basis of the types of measurands, methods and systems, time, periodicity or continuity of measurements. For the first time, the core and essential procedure of monitoring is emphasised, whilst design guidelines and asset management procedures may fail to take into account. With monitoring, as part of digital innovation in transport infrastructure, the data collection and interpretation is performed, defining the structural integrity and the level of operability and/or functionality of the networks. The interpretation of the data is a first assessment of the extent or severity of the identified damage and the potential risk relevant to the asset condition.

Decision-making, represented by diamonds in the flow chart, is performed on the basis that safety is the main criterion. This is either followed by updating the monitoring strategy in the case of acceptable risk or either by further risk assessment when the condition is non-acceptable. Recently, the operations of the transport networks have increasing demands and the requirements, except for safety, have been shifted toward minimal tolerance to traffic disruptions. This shift is also expressed by the requirement for enhanced resilience, both locally (component) and globally (asset or network). In case the integrity, operability or functionality is in question, further evaluation of the risk is performed. This evaluation inherently includes all epistemic uncertainties as these are integrated into the fragility and degradation models, as described in the orange activities (updated design\& assessment model) of the flow chart. The estimated level of risk defines the asset operability, and in this case, monitoring can continue, thus the risk is acceptable. For the assets that have the greatest impact to the resilience of the network, projections of the risk to the future may lead to the need for additional adaptation measures e.g. for climate deviations, increase in requirements, deterioration. Otherwise, the next step is to deploy mitigation measures, when the risk is unacceptable. The nature of the measures varies and spans from decisions for communicating risk to stakeholders, to legislation amendment, as a means to protect the infrastructure, the environment or ownership and property, measures aiming at addressing inadequacies of the design guideline requirements. Measures might include engineering restoration and additional secondary direct or indirect task, for example, additional signalling to reduce risk due to slippery road surface. These mitigation measures may also include actions for adaptation, which will upgrade the asset and/or the network functionality back to its original performance or higher. This adaptation might also embrace updating of the monitoring strategy, e.g. by adding new and/or upgraded sensors.

The roadmap also prescribes improvements for both the monitoring strategy and the infrastructure models throughout the lifespan of the transport system, when resources are available. These upgrades may be aided by emerging technologies, e.g. Building Information Modelling (BIM) (Friswell and Mottershead, 2013; Love et al., 2015; Bruno et al., 2018 ), Internet of Things (IoT) (Tokognon et al., 2017; Abdelgawad and Yelamarthi, 2017) or Digital Twins

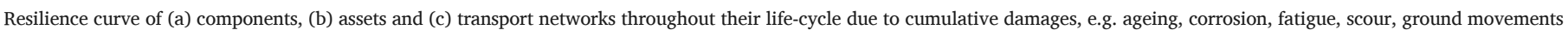
and settlements, deflections, increased traffic (see $\mathbf{1 a}, \boldsymbol{b}, \boldsymbol{c}$ ), natural and human-induced hazards, e.g. seismic events, flash floods, landslide and fire (see $\mathbf{1 d}, \boldsymbol{e}, \boldsymbol{f}$ ) and figure nomenclature (1g). 


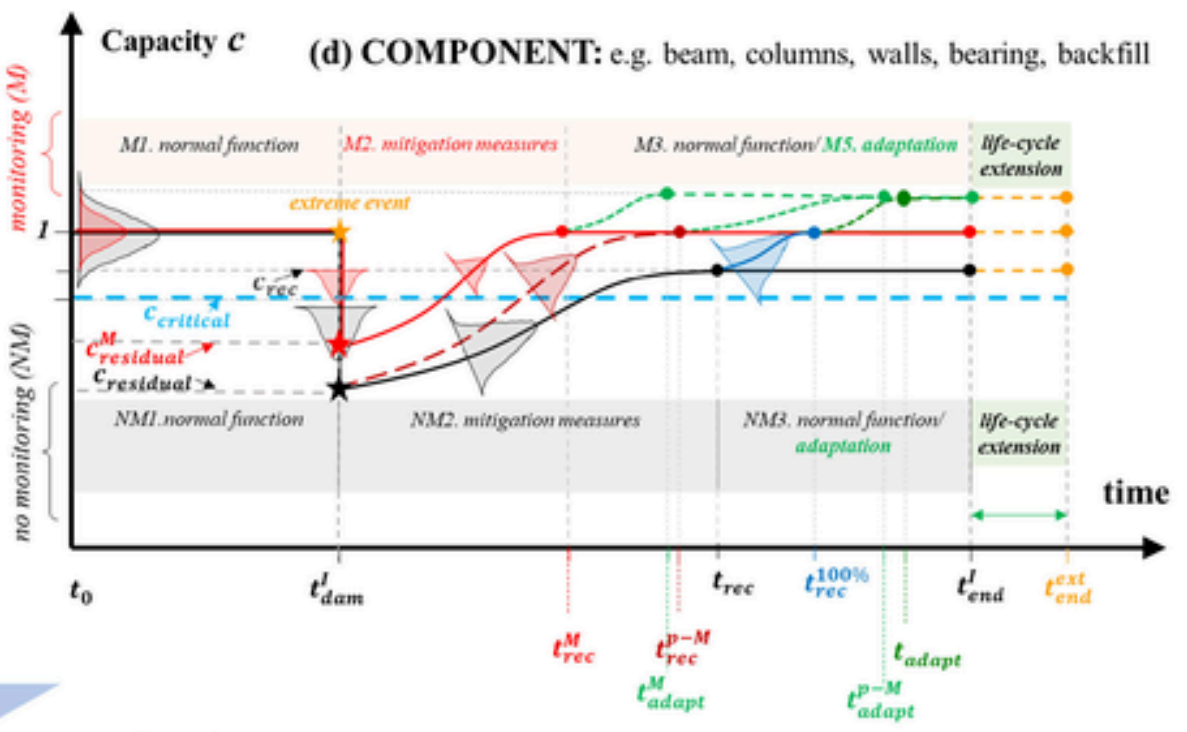

Monitoring strategy of systems

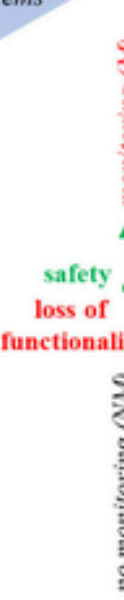

Capacity $c$

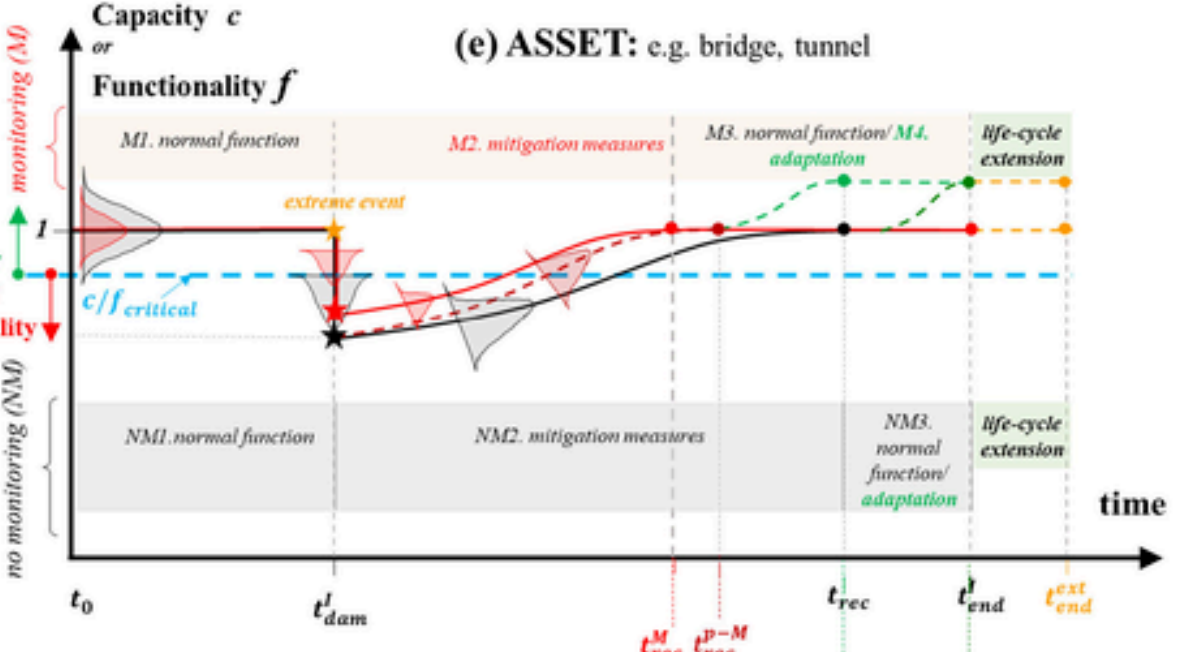

Risk assessment $t_{\text {rec }}^{M} t_{\text {rec }}^{p-M}$

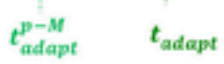

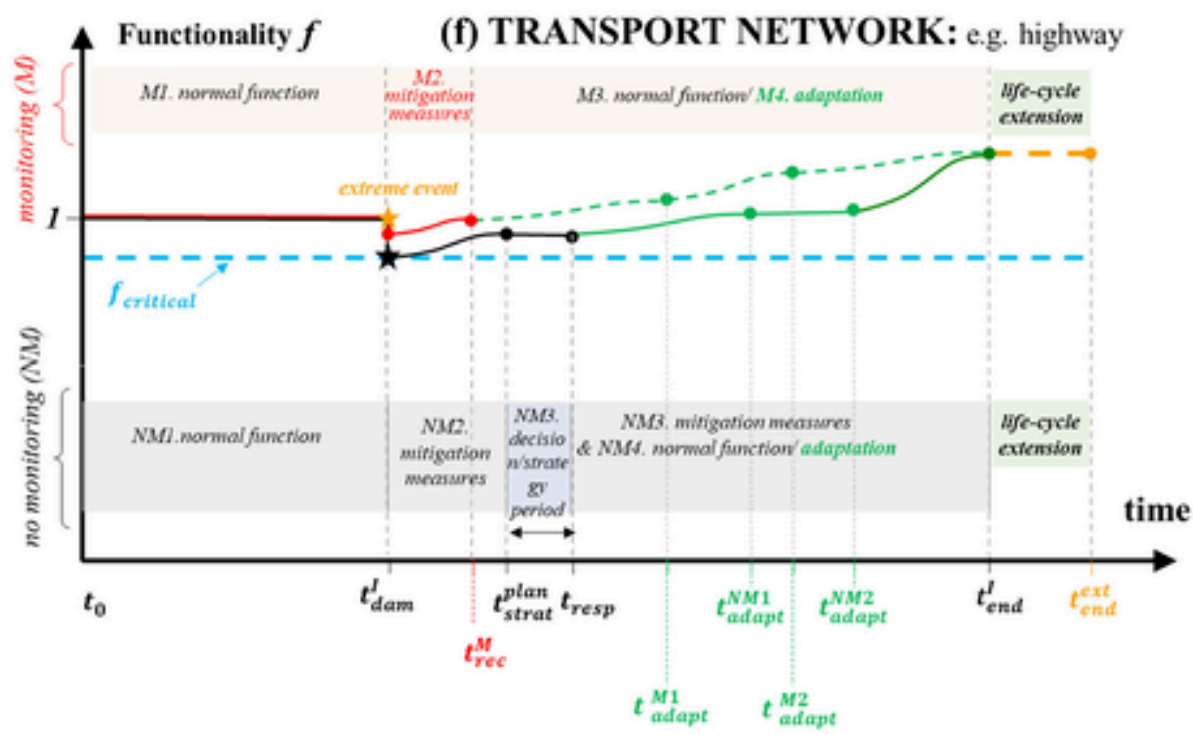


(g) Nomenclature:

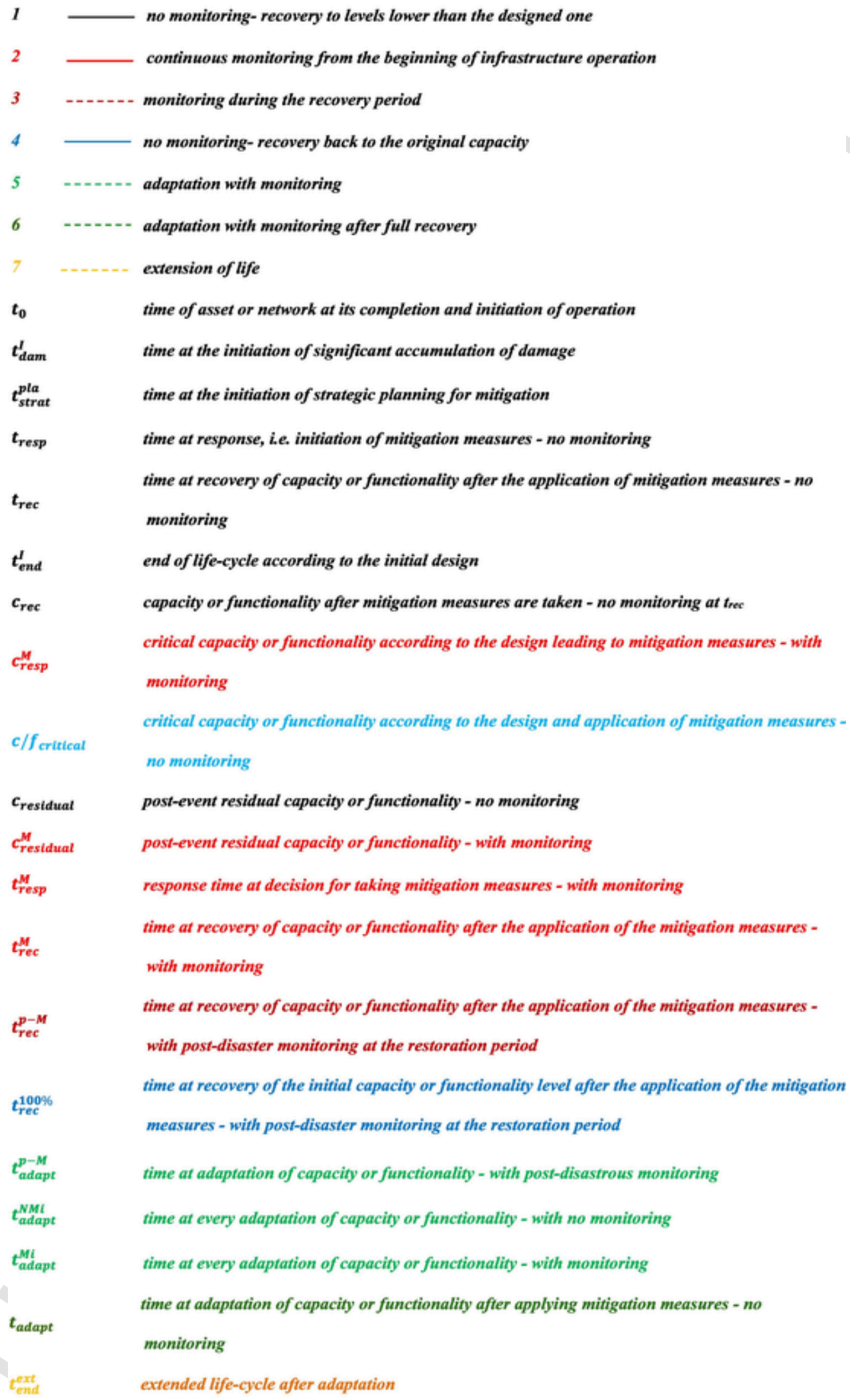


(DT), Machine Learning (ML) (Wang et al., 2019) and Artificial Intelligence (AI) (Zhang et al. 2013; Yi et al., 2016; Alavi et al., 2016) among others. These technologies are valuable tools providing intelligence during the risk assessment, interpretation and decision-making (orange sub-procedure). They enable processing big data and permit the development of models for predicting future combined events. The augmented reliability level helps trigger early warnings. Digital technologies can further facilitate early warnings (Gasparini 2007) permitting optimum, safe and non-disrupted traffic, as a means to minimising economic and human losses.

\subsection{Use of emerging monitoring technologies in risk management and adaptation}

It is expected that future developments will include the integration of new technologies in the data-driven risk and resilience assessment of transport infrastructure toward adaptation to changing climate, environment and future demands (see Emerging Technology in Fig. 3).

Machine Learning (ML) techniques can reduce drastically the time and resources required for efficient model updating and generation of vulnerability and resilience models. ML has been utilised successfully to date for the rapid seismic fragility assessment of bridges (Mangalathu and Jeon, 2019; Kiani et al., 2019). However, ML can also be employed for the resilience assessment of infrastructure exposed to diverse hazards and can be enhanced by monitoring data. Liang et al. (2016) investigated the use of ML algorithms for evaluating the serviceability of bridges using combined SHFM data generated by external loads, such as wind and traffic flows, hyperspectral images and moisture measurements of the structural components. Roshandeh et al. (2014) explain how Big Data and cloud computing can be utilised in real-time decision-making for critical bridges based on SHM data, including communication of warning messages to drivers via Variable Message Signs (VMS) to cell phones. BIM is also expected to be utilised extensively in risk and resilience management, not only during the design and construction of transport infrastructure projects, but also during their maintenance, design of mitigation measures and extension of lifetime (Zou et al., 2017). Yet, a knowledge gap existing in the integration of BIM technologies with traditional risk management.

In the near future, ML and BIM are expected to cooperate and complement IoT technologies (Song et al., 2017) for delivering smart transport infrastructure, toward providing efficient and new transport functions and services to the end-users. Inevitably, IoT and related technologies, e.g. AI, data analytics, will assist transport infrastructure owners and operators in monitoring and managing ageing structures more effectively in almost real-time. For example, Whyte et al. (2019) explored the feasibility of using digital twins for providing insights into infrastructure system interdependencies. The research embraced practical identification, prioritisation and management of system interoperability.

\section{Structural Health and Functionality Monitoring (SHFM) of transport infrastructure: methods and technologies}

\subsection{Sensing technologies for SHFM}

This section includes a description of traditional and advanced sensing methods for monitoring infrastructure assets and networks, such as highways, railways and transport hubs. A systematic literature overview was conducted based on: i) relevant keywords (e.g. monitoring, transport, infrastructure, NDTs, sensors, airborne, terrestrial), ii) publications mainly published over the last five years, iii) peer-reviewed scientific papers highly cited and reports from important research projects and initiatives, including standardisation committees.
The review is summarised in Tables A.1 \& A.2 (see Appendix A), in which the main techniques are classified (Scott et al., 2003; ASTM D $4580-86,1992$ ), based on the function principle (Gastineau et al., 2009; McCann and Forde, 2001; Fujino et al., 2019) and the measurands (SHM, 2013), as well as the usefulness in assessing risk and resilience (Yang and Frangopol, 2019), their advantages and disadvantages or limitations in application. Table A.1 summarises the most important non-destructive tests NDTs and also discusses whether instrumentation is required, or measurements can be taken remotely or contactless. Table A.2 summarises the advantages and disadvantages of the methods, and their cost i.e. low, moderate, high, as an estimation of the resources and equipment required, and their practicality in risk and resilience assessments.

The owners, operators and stakeholders, who manage infrastructure, are responsible for the collection, interpenetration and secure retention of monitoring data. Based on these archived data, the structural integrity is documented and reports on the safety evaluation of the asset and the functionality of the network are assembled. The documentation includes evidence from the frequent inspections in structural and non-structural members (AASHTO, 2000; AASHTO, 1998). The most common SHFM method is the conventional visual inspection (FEMA, 2017; Karabinis and Rousakis, 2010; Scott et al., 2003) of infrastructure and networks, which is historically the most traditional and direct engineering method. This has always been raising the question of defining the suitable frequency of inspections or what is the most efficient method to inspect inaccessible members or long-distant members, e.g. foundations, pipelines, rebars. This approach contains subjectivism and uncertainty, as it is predominantly based on visual examination, experience and engineering judgement. Moreover, except for the practical difficulty of accessing hidden parts, assets present minute cracking, which is not always detectable visually or by applying simple inspection equipment, commonly used in practice, such as magnifiers. These cracks might be proven important to the global performance of the asset and its detection is not possible visually, but only when its impact is disastrous for the operation of the infrastructure e.g. fatigue cracks, propagated corrosion). Monitoring methods, including NDTs, are very popular in transport infrastructure because they are less invasive to the critical members and provide numerous measurands (see Appendix A, Tables A.1 \& A.2).

The ongoing digital revolution and advanced material science have introduced significant innovation and have completely reformed monitoring techniques. Starting from the times of the simple visual inspections, the evolution of sensing technology and miniaturisation of sensors and novel NDT, as well as the enhanced computer power, has offered many options for recording diverse measurands. All these techniques, listed in Appendix A, add value to the damage detection and provide feedback for the health and functionality in an expedient and objective manner. Monitoring techniques can be (Appendix A: Table A.1) contactless (C), distant (D), wireless (WL), instrumented (I), autonomous (AU), unattended (U), aerial (A), terrestrial (T). Lately, significant attention has been paid to the remote, wireless sensing, smart and digital means of recording of vast information and big data obtained almost real-time. More specifically, unmanned aerial technology, e.g. drones, helicopters, has been extensively used. A drone-enhanced inspection enables expedient access to areas that may pose health, safety and environmental risks. Drone inspection is the preferred method for visual surveys across a wide range of transport infrastructure applications as it is safe and accurate (Eschmann and Wundsam, 2017; Omar and Nehdi, 2017). Equally, traffic cameras and unmanned aerial vehicles (UAV/Drones) are very promising means in asset management of transport networks (Greenwood et al., 2019), which can provide both qualitative and quantitative evidence and data. 
Fig. 1. Continued

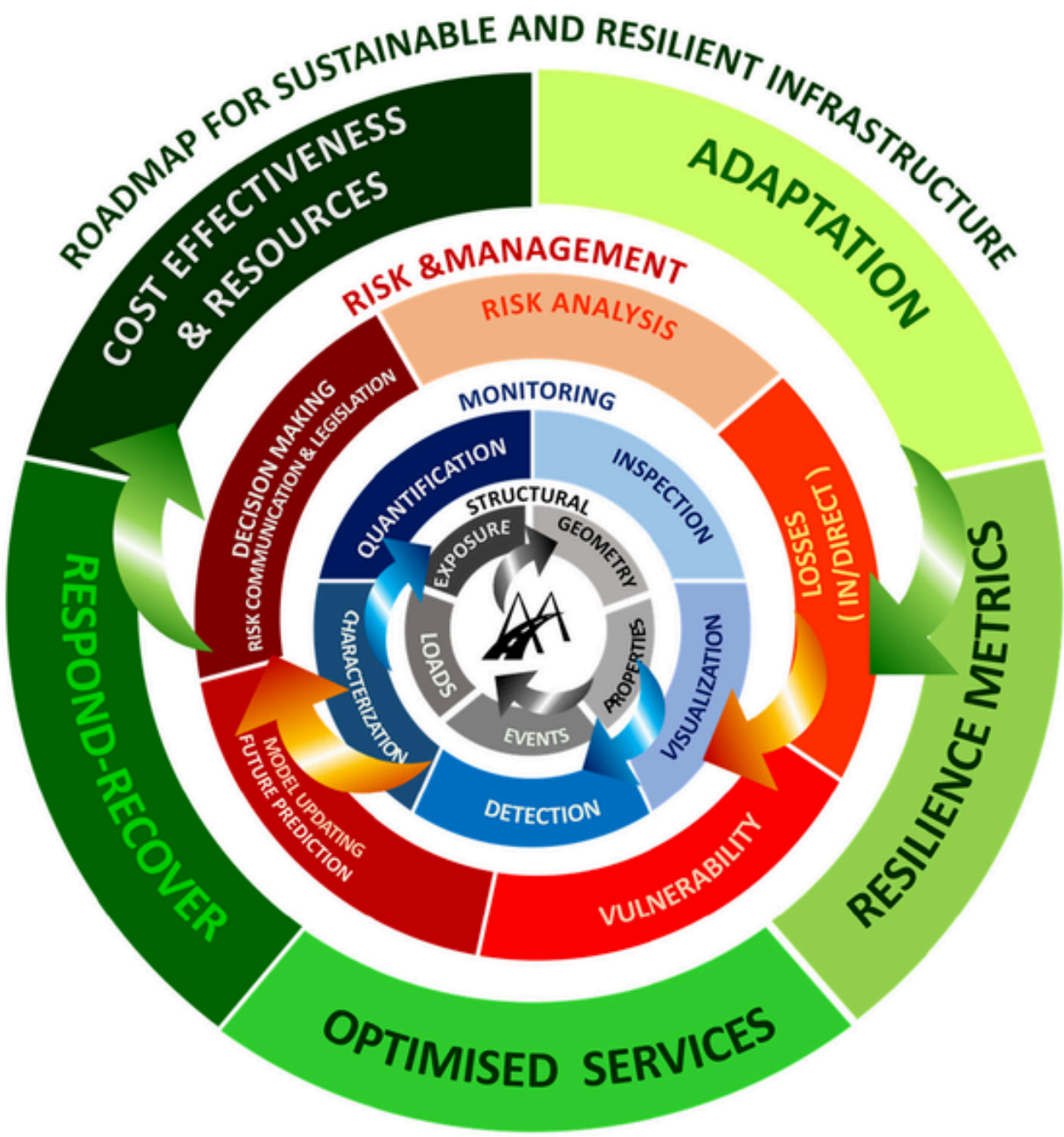

Fig. 2. Holistic approach for delivering monitoring-based resilient infrastructure.

There is a number of research projects further studying the development of novel and advanced, digital, unmanned, automated monitoring devices, e.g. scanning cars, such as Trimis, Smart Structures, Sustainable Bridges, Smart Structures, Memscon, Isms, Wi-Health, Cross-It, Bridgemon, Rpb Healtec, Senskin, Cobri, Aerobi (Gkoumas et al., 2019).

\subsection{SHFM data analysis methods}

Both physics-based and data-driven methods are developed and combined to visualise the damages on infrastructure. In transport infrastructure, the exposure conditions, the failure patterns, and the consequent traffic disruptions (Ganin et al., 2019) are crucial parameters that enable the quantification of the remaining capacity of structural members as well as defining risks. In practice, a combination of monitoring systems is applied especially in landmark and/or critical infrastructure (Ko and Ni, 2005; Xu, 2012). Physics-based methods provide accurate results regarding the visualisation of the crack patterns or changes in geometry or at the mechanical properties of materials (Skarżyński and Suchorzewski, 2018; Hoult et al., 2016), for example, Digital Image Correlation method. Further characterisation requires, in most cases, further documentation and tests for result valida- tion, that is, semi/non-destructive testing (NDT). The characterisation of damages is often challenging. For example, if wave propagation and ultrasonic methods are used for detecting, mapping and characterising damages within assets, the interpretation of the scattering field or the decomposition of the wave modes in time or frequency domain is time-consuming and complex (Palacz, 2018; Ou et al., 2017; Achillopoulou and Pau, 2017; Pau et al., 2016; Chatzi and Spiridonakos, 2015; Pavlopoulou et al., 2013; Xu et al., 2009; Rose, 2004). This means that further processing is needed based on the geometry and the mechanical properties of the asset or the interoperabilities of the network.

Monitoring requirements tend to increase nowadays, and there are cases of technologically advanced countries e.g. Japan, where real-time continuous data have been recorded for many years, for instance the Yokohama Bay, Rainbow or Tsurumi Fairway Bridge (Fujino et al., 2019; Fujino and Siringoringo, 2011). The so-called data-driven methods aim at streamlining the big data obtained with the interpretation of results, especially if the objective is to expediently quantify the resilience of critical infrastructure by using SHFM systems (Lloyd's Register Foundation, 2014). 


\section{EXPOSURE | HAZARDS | INTERACTIONS}

stressors | natural, environmental \& human induced or multiple hazards, normal \& extreme events, ever changing environment, adaptation to climate change $\&$ demands due to increased traffic loads | interaction with eco-system \& networks

\section{START

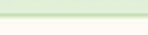

है

a

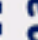

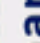

$\varepsilon$

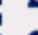

ข

宩 resilience

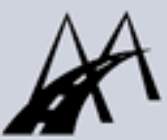

e.g. local, global, continuous, short-term, measurands, selection of method-systems

\section{INTERPRETATION OF DATA}

visualization, quantification, characterization, damage detection

Criteria: safety- undisrupted operation, functionality, emergency accessibility services

UPDATED MONITORING CLIMATE CHANGE

e.g. repeatability, method-system

Sustainable

$\&$ Resilient

Infrastructure

MITIGATION | ADAPTATION PRIORITIZATION COMMUNICATION OF RISK legislation- natural \& built environment direct engineering: e.g. repair, retrofitting other: e.g. early warning systems, insurance

tnon-acceptable resilience

Criteria: safety, undisrupted operation, functionality, emergency accessibility services, minimization of losses, environmental impact, restoration strategies

(type, time, resources)

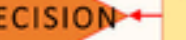

risk

\section{acceptable *}

\begin{tabular}{|c|c|}
\hline RISK & RESILIENCE \\
hazards, & agility, preparedness, \\
vulnerability, & recovery, \\
adaptation
\end{tabular}

\section{UPDATED DESIGN} \& ASSESSMENT MODELS stress levels, performance, loads, future risks, fragility \& degradation models

EMERGING TECHNOLOGY e.g. BIM, digital twin, Internet of Things (IoT), Cloud, Machine Learning (ML), Artificial Intelligence (AI)

\section{E NETWORK OWNERS/OPERATORS}

efficient short \& long term management, cost savings
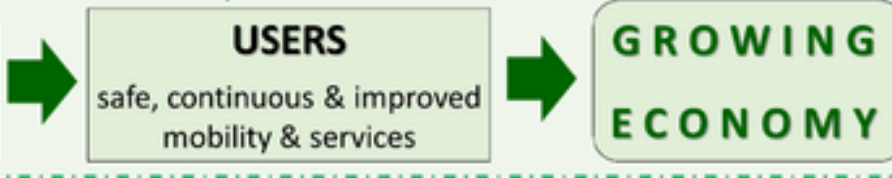
Fig. 3.

\subsection{Deploying SHFM data in risk and resilience evaluations}

The vast of monitoring and sensing data and evidence, which is available to transport asset owners, remains unexploited (Webb et al., 2015). This wealth of information provides reliable means for producing accurate and rapidly informed QRAs and resilience quantification for critical transport infrastructure. Yet, SHFM data are rarely integrated, mainly due to the diversity of input and output data, as well as the variability of the interpretation methods (Chatzis et al., 2015). These models can provide the basis for an automated process to evaluate the current structural and functionality state of a transport asset in an accurate and expedient manner in support of decision-making for mitigation and restoration measures, aiming at delivering undisrupted and safe networks with enhanced resilience. It is also recognised that cascading risks are found to be very relevant these days and inevitably, make risk and resilient assessments more challenging. For example, cascading effects of multiple geological hazards like earthquake and tsunami, or cascading effect of geohazards and climate hazards, are more difficult to be monitored, because different stressors have different effects on transport assets. However, integrating heterogeneous data is possible to provide a more holistic evaluation of risk and resilience by providing a better understanding of the sequence of events and map more accurately the impact on the assets and networks. An integrated record can providevidence for the quantification of resilience directly or indirectly as per Table A.2, Appendix A. The raw data can provide directly information with regard to the existence of damage or deterioration. Monitoring data can also indirectly assist in the quantification of the losses, robustness and redundancy during disturbances. Additionally, data provide evidence about the idle or restoration time needed for the asset to recover and the rapidity at the adaptation phase of the network (Connelly et al., 2017). The latter can be used as the components of a resilience matrix, considering risk, reduced losses for increased sustainability and adaptation capacity in transport infrastructure, analogously to Marchese et al. (2020).

Many techniques or instruments are suitable for monitoring multiple measurands directly or by indicating estimations of the vulnerability or robustness of assets. The damage tolerance of an asset is an indirect quantification of its robustness. As such, the use of linear variable differential transformers (LVDT) is the preferred method for recording displacements as well as pressure, force level and stress flow (Joshi and Harle, 2017). Also, they measure deflections, cracks, expansion of joints and can help in rating stress states indirectly and evaluating the changes in natural frequencies or degradation of stiffness (Kohrangi et al., 2016). These strong indications of damages or deterioration, especially when exceeding specific defined and permissible design limits can facilitate the estimation of the asset's vulnerability (Kappos, 2016). This knowledge is useful during the idle time during which the asset is not fully operational, to accelerate decision-making for restoration.

Equivalently to traditional SHM measurands, all the records of monitoring can indirectly be used for defining the probability density function (PDF) of specific intensity measures and therefore the risk. For example, levels of heat can be directly assessed by records of temperature. The latter is helpful during the idle time, e.g. the decision-making, for taking mitigation measures swiftly, because the risk can be quantified more accurately when temperature is known. In this example, the record of the hazard, e.g. a potential fire outbreak, due to the elevated temperatures expressed by a distribution, is an input for computer- based models to estimate fire risk. Functionality Monitoring (FM) gives an inverse value to the resilience assessment. Counter to structural health monitoring (SHM) systems that give measurements and directly estimate the loss of the capacity, FM may provide information for assessing, indirectly, the preparedness and response. For instance, traffic records can be used as an indicator of the functionality of the asset i.e. records of the traffic flow, but can also provide feedback to commute models and assist in estimating increased traffic demands.

Nowadays, there are efficient protocols and technical guidelines for the utilization of the various monitoring systems, yet there is a lack of strategies that describe a step by step methodological approach for the monitoring of transport networks for obtaining the data needed for planning and managing on the basis of resilience, i.e. enhancing response and accelerating recovery. What is more, the condition of transport assets, residing within ecosystems of the built and natural environment, is dependent on a large number of structural and non-structural or non-engineering parameters, e.g. facility networks, pollution, fauna, and hence the impacts of these parameters to normal and emergency operation of the transport assets should be assessed. Yet, it relies on the stakeholder's responsibility to utilise the monitoring systems throughout the life-cycle of the asset and record the evolution of their response within these ecosystems (Webb et al., 2015).

Traditional methods for data analysis, for the detection and characterisation of defects, as a criterion for the decision-making and management of the asset and network, have generally a reduced level of reliability. The evolution of computing power enables the use of model updating and machine learning algorithms to speed-up the time-consuming data processing. These algorithms can reduce errors and misclassifications due to human omissions (Farrar and Worden, 2012; Yi et al., 2012; Simoen et al., 2015) or reduced equipment's accuracy by using artificial neural networks or deep learning algorithms for pattern recognition-based automated-signal classification (Azimi et al., 2020) (see also Section 4 \& 5 below). This approach can potentially lead to improved efficiency of damage detection analysis based on big data and the higher reliability of the NDT results and traffic models.

\section{Physics-based methods for monitoring-enhanced resilience quantification}

Transport infrastructure management relies heavily on the continuous feedback from SHFM systems for the assessment and prognosis of the capacity of the assets and the functionality of the networks (Chen, 2018). This process includes the diagnosis of the damages to allocate resources on disaster mitigation and recovery actions. For the design, assessment and prediction of performance, currently, there are models available for simulating assets and networks. The validation of these models is typically achieved by comparing SHFM measured data with the engineered predictions' values (model). The latter explains the benefit for monitoring, which essentially provides valuable and accurate input data of monitored infrastructure assets, which are then used in model updating (Simpson et al., 2019). Continuous SHFM feedback can potentially provide evidence of asset and infrastructure responses and hence means of evaluating capacity and functionality for normal and emergency circumstances, e.g. after natural disasters, which is useful for accurate and rapid quantification of risk and recovery. The output of this procedure, known as model updating, is practically the procedure to obtain an accurate representation of the structural condition and functionality of the asset in real-time (Abdeljaber et al., 2017), toward resilience-based infrastructure management. 


\subsection{Model updating}

Model updating is described to emphasise the importance of reducing the uncertainties of prediction models based on monitoring data with various sensitivities. It aims at finding the best match of numerically derived parameters with the ones obtained from the monitoring systems (SHFM), by changing iteratively physical parameters in the numerical model, using an optimisation algorithm. It is a typical inverse dynamic problem, which was used to calibrate and/or verify the numerical model (Friswell and Mottershead, 2013). In recent years, model updating has been used to identify structural damages, based on the data from SHM systems (Jaishi and Ren, 2006; Teughels et al., 2002). The methodology can be realised in two steps. Initially, the numerical model, for instance, a finite element model (FEM), can be updated based on the structural data in a healthy or as-designed state. This is the calibration step, which ensures that the model can produce output with very similar, if not the same, responses as the actual structure under the same actions. In the second step, the calibrated numerical model is updated based on actual, SHFM-based, structural responses whilst being in the damaged state. This is the identification step that leads to structural damage detection, localisation, characterisation and quantification.

The inverse problem is essentially an optimisation process, i.e. algorithm, which is controlled by three key factors. First, the input variables, which are to be optimised, should be selected and be bounded by some prescribed ranges, which are determined according to the degree of uncertainty that governs the input parameters. Second, the comparison of measured data and prediction results in a set of equations that need to be combined to obtain the updated output (Fig. 4). This is the so-called objective function (OF), which should be mathematically well-defined as described in Bruns et al. (2019). Third, the optimisation should be carefully selected. Numerous efforts have been made based on vibration responses. Traditionally, modal parameters, such as natural frequencies, mode shapes, and their derivatives, have been widely used as the objective function. More recently, model updating has been realised based on responses measured by various non-destructive testing (NDT), e.g. vibrations, strains, displacements (Wang et al., 2011a; Pedram et al., 2016; Wang et al., 2011b). Civil infrastructure systems are normally very complex, and thus their numerical models contain a large number of variables (Chkrebtii et al., 2016). This large number of input variables creates, in most cases, complexity for the mathematical solution, since far more variables exist than the equations derived of the objective function, resulting in an undetermined problem. Thus, there is a range of solutions concerning the input for the infrastructure model, which can match the real asset. As such, the reduction of the variables is essential in defining a determined problem with a unique solution. The reduction of the number of variables is achieved with different methods e.g. sensitivity analysis (Mottershead et al., 2011), substructure method (Weng et al., 2011) and damage function method (Jaishi and Ren, 2005). After the establishment of the optimisation, the solution remains challenging, because the objec- tive function (OF) is usually nonlinear (Jaishi and Ren, 2005). Hence, the relationship between the results of the asset model and the actual structure is not linear. Many reasons contribute, among which the changes of the exposure of the structure in environmental conditions, change of ecosystem, the material response over time, undetected cumulative damages and construction imperfections (absorption period). The solution of the inverse problem is a time-consuming and tedious mathematical task. As a result, selecting a powerful optimisation algorithm is an important task. There are numerous algorithms for optimisation, including traditional ones e.g. gradient-based (Neftci et al., 2019) and intelligent ones (Alkayem et al., 2018). For example, the Estimation of Distribution Algorithm (EDA) is an efficient one (Wang and Zhang, 2013), as it can provide both the updated parameters and the distributions of the updated parameters.

Data-driven models, such as the SHMnet (Zhang et al., 2019), can be part of the updating as well (deep-learning). The FEM that represents the asset is typically used for the prediction of its performance, but they can be substituted by reduced-order models that parametrise the physical properties. These methods are helpful in the identification and quantification of damages (Simpson et al., 2019). As such, model updating has the potential to become a general principle in the SHFM field especially since accuracy is guaranteed and enable the quantification of the risk and resilience.

\subsection{Uncertainty in resilience quantification}

Model updating can be a useful tool for the direct quantification of the losses, the robustness and indirectly the functionality and risk of the network. Hence, the resilience of an asset and in extension the resilience of a transport network can be continuously evaluated with measurements of high reliability. This reliability of monitoring data is vital for obtaining updated results that are realistic and can predict future responses with confidence. The accuracy of the updated output is mainly dependant on the accuracy of the input data (Loucks and Van Beek, 2017). Given a specific uncertainty level of the input data, either derived by monitoring measurements or on the basis of assessments, the uncertainty of the output and hence the reliability is linked to the level of sensitivity enabled in the data acquisition. Sensitivity is the ability of sensors to properly record changes, especially minor ones. The sensitivity is associated with the nature of the measurand e.g. peak ground acceleration (PGA), flood rate or the mechanical properties of an asset, such as strength, resistivity or deflection. The sensitivity also depends on the type of instrumentation used, i.e. piezoelectric actuators or compatible accelerometers.

The shift from traditionally assessed input to monitoring-enhanced and data-driven updating of models reduces the uncertainties (Abdeljaber et al., 2017). Fig. 5 illustrates the updated output uncertainty probability density functions for traditional assessed parameters (blue) or monitored ones (orange) with different sensitivity levels (low denoted with light colours, high with dark). For the same level of uncertainty of the input data, the updated output uncertainty is decreased when input data are based on monitored parameters if compared to the

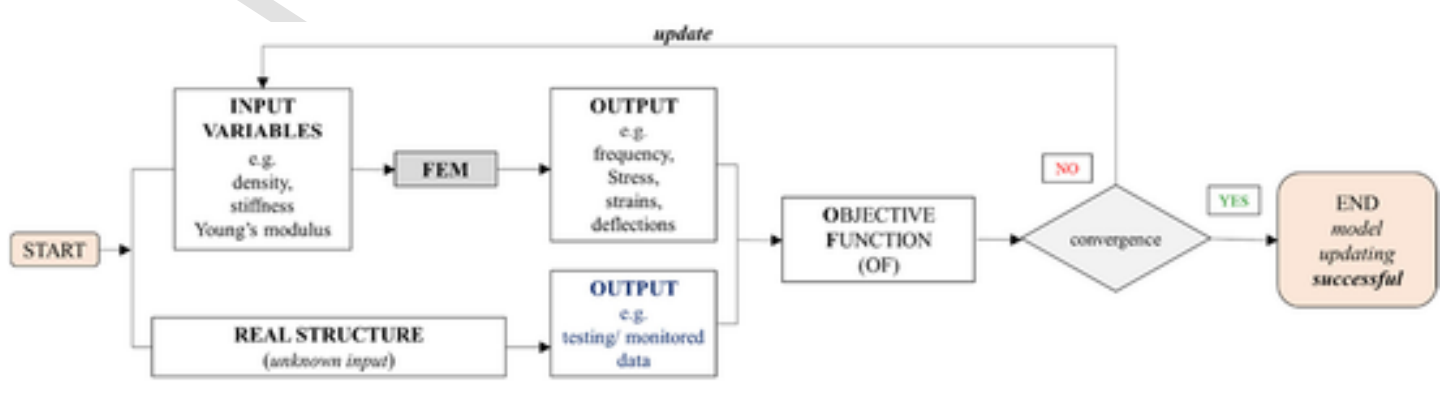

Fig. 4. Optimisation algorithm for model updating. 
Sensitivity level of parameter

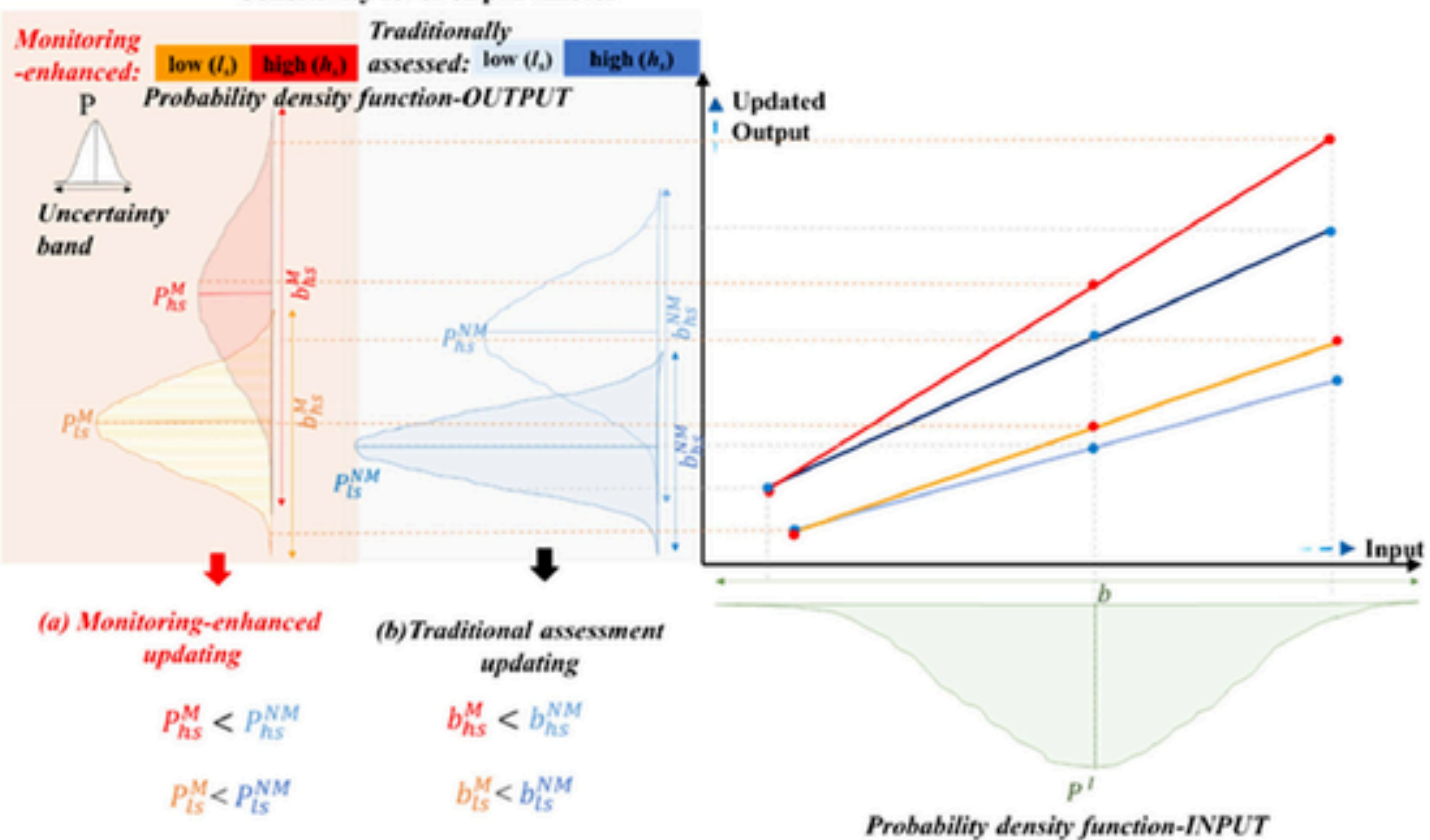

(c) Nomenclature:

ls low sensitivity

hs high sensitivity

- traditional assessed input data of variable with high sensitivity monitored-enhanced input data of variable with high sensitivity traditional assessed input data of variable with low sensitivity monitored-enhanced input data of variable with low sensitivity

$P^{l} \quad$ uncertainty probability of input data

$P_{l s}^{M} \quad$ uncertainty probability of monitored-enhanced input data of variable with low sensitivity

$P_{l s}^{N M} \quad$ uncertainty probability of traditionally assessed input data of variable with low sensitivity

$P_{h s}^{M} \quad$ uncertainty probability of monitored-enhanced input data of variable with high sensitivity

$P_{h s}^{N M} \quad$ uncertainty probability of traditionally assessed input data of variable with high sensitivity

b uncertainty band of input data

$b_{h s}^{M} \quad$ uncertainty band of monitored-enhanced input data of variable with high sensitivity

$b_{h s}^{N M} \quad$ uncertainty band of traditionally assessed input data of variable with high sensitivity

$b_{l s}^{M} \quad$ uncertainty band of monitored-enhanced input data of variable with low sensitivity

$b_{L s}^{N M} \quad$ uncertainty band of traditionally assessed input data of variable with low sensitivity

Fig. 5. Impact of the sensitivity level of measurands in model updating output (a) assessed input values, (b) monitored input values, (c) nomenclature. 
input from traditional inspections $\left(P_{l s}{ }^{M}<P_{l s}{ }^{N M}, P_{h s}{ }^{M}<P_{h s}{ }^{N M}\right)$. In this case, the uncertainty band of the updated output is also wider $\left(b_{h s}{ }^{M}<b_{h s}{ }^{N M}, b_{l s}{ }^{M}<b_{l s}{ }^{N M}\right)$ and corresponds to a lower amplitude $\left(P_{l s}{ }^{M}<P_{l s}{ }^{N M}, P_{h s}{ }^{M}<P_{h s}{ }^{N M}\right)$ for both types of sensitivity and any level of uncertainty of the input data.

Section 5Section 5Two highly sensitive parameters $\left(h_{s}\right)$ can be considered, one continuously monitored, e.g. peak ground acceleration measured by seismograph stations, and another one that is assessed during inspections, e.g. deflections. The model updating output based on the intensity measure of PGA provides damage estimation more reliably. Deflections, when assessed by measurements made with reliable instrumentation, are not traditionally recorded in time-histories and envelop curves, like earthquake motions. They are useful for further estimating other parameters e.g. stiffness, which is considered of low sensitivity $\left(l_{s}\right)$. Based on these assessments, the quantification of the losses of the structural capacity is possible. There are also, direct metrics of low sensitivity parameters. For instance, the corrosion propagation is quantified by various sensors i.e. microcells, anodes, LPR, even though the sensitivity to the corrosion rate is limited. Further to the updating and prediction, Section 5 describes other metrics that predict also future disturbances due to external stressors and hazards.

\section{Monitoring-enhanced resilience assessment models and their applications}

This section provides insights on how the vast of monitoring data available to transport asset owners can be utilised to improve the accuracy of the theoretical models and reduce uncertainty for risk and the quantification of resilience. Thus, the section is in support of the roadmap presented in this paper on the SHFM-based resilience assessment of transport infrastructure, including the important components of risk and resilience, i.e. hazard, exposure, vulnerability, preparedness, response and restoration. In this respect, monitoring data-driven risk and resilience assessment of transport infrastructure exposed to multiple hazards is described for improving transport asset management using the new technological developments (Wolf et al., 2015; Gkoumas et al., 2019).

\subsection{Hazard assessment}

Hazard is usually defined with maps and models, developed based on records and historical data, providing, for example, the annual probability of exceeding a certain level of a specific hazard intensity measure, e.g. peak ground acceleration for seismicity or water discharge for flood, sea level rise for climate change. Therefore, monitoring systems can provide input for updating available hazard models, accounting for the sensitivity level and nature of the hazard measures, especially for critical infrastructure, exposed to diverse hazards. For example, long-term measurements of gauging stations on river-crossing bridges or remote sensing can be used to update site-specific hazard models and calibrate hydrological models (Jian et al., 2017; Lamb et al., 2017; Dottori et al., 2016; Coxon et al., 2015) required for the vulnerability and risk analysis for floods. Data from diverse sensors directly placed on an asset can facilitate the real-time assessment of hazard such as the scour depth at the bridge foundations, the river flow or debris accumulation. For example, Crotti and Cigada (2019) applied different monitoring systems on a river crossing bridge. They installed an anemometer, a hydrometer, video cameras and an echo sounder together with a novel device, measuring wind direction, water level, accumulation of debris and temperature difference calculating riverbed level, respectively. The bridge safety could be assessed accounting for multiple hazards in real-time by estimating the foundation scour, the wind or water drag forces and the effect of debris exerting on the pier.

\subsection{Exposure}

Mapping of inventory and analysis of the exposure of transport infrastructure are key components of reliable disaster risk assessment (UNISDR, 2009) and can be translated into traffic disruptions, economic losses, injuries and/or fatalities and environmental impacts. Exposure is typically obtained from databases and census data or by in-situ surveys, which are characterised by high-cost and, in many cases, by relatively low accuracy and/or lack of essential information for risk assessments (Wu et al., 2018). Monitoring systems can enable accurate evaluation of infrastructure exposure and enrich inventories, and thus, reduce the relevant uncertainties. For existing infrastructure, that the available databases are limited, or, unavailable, remote sensing provides fast and low-cost retrieval of exposure data with sufficient accuracy (Li et al., 2017; Acton, 2016). In this context, LiDAR systems have been used extensively to obtain information for the road geometry, e.g. lane width, slopes, and the road environment, e.g. road markings, street signs, vegetation, traffic light poles, (Ehrlich and Tenerelli, 2013). Moreover, exposure datasets and transport models can be retrieved through Open Street Maps, Google maps and high-resolution imagery using different algorithmic procedures (Ehrlich and Tenerelli, 2013; Gil, 2015; Wang et al., 2016).

\subsection{Vulnerability}

Vulnerability is commonly quantified with fragility functions, providing the probability of the asset to exceed defined limit states for a hazard intensity or demand level of interest. Fragility functions can be derived from empirical, analytical, expert elicitation and hybrid approaches and especially for transport assets are based on numerical simulations (Argyroudis and Kaynia, 2014; Billah and Alam, 2015; Gidaris et al., 2017). Fragility functions are usually expressed through a lognormal cumulative distribution for each damage state, described by a median value $\left(\mathrm{IM}_{\mathrm{mi}}\right)$ and a logarithmic standard deviation $\left(\beta_{\text {tot }}\right)$. The latter represents the uncertainties including the variability in the actual demand $\left(\beta_{\mathrm{D}}\right)$ at which a damage state is likely to initiate, the variability in the quality of construction and the loading history (Nocera et al., 2019). Accurate measurements of SHM methods can decrease the variability in the capacity $\left(\beta_{C}\right)$, due to uncertainties in the geometry and material properties of the asset, and the variability in the definition of the limits states ( $\beta_{\mathrm{LS}}$ ) (Porter, 2015; Argyroudis et al., 2019) and hence the total uncertainty $\left(\beta_{\text {tot }}\right)$ can be reduced. The indicative fragility curves, shown in Fig. 6, illustrate the effect of monitoring data in the fragility estimations. The blue curve represents the ideal model, which has very low or no uncertainty, and therefore, is almost vertical. This means that for a given stressor or intensity measure the damage is known. The continuous black fragility curve is estimated based on the initial model $\left(\mathrm{t}_{1}\right)$, without any monitoring data considered during the assessment. If the properties and geometry of the asset are updated based on monitoring measurements, then the uncertainties in the fragility are reduced. This is shown with the dashed black curve which is steeper than the solid line.

Long-term monitoring data, such as vibration data, can be used to track changes in the structural system (see Section 3). These measurements can provide data for the safety and risk assessment of the structure, as well as for the time-dependent fragility analysis of the asset. The same information can be used to update the numerical model of the structure (Section 4), and consequently, to update the estimated fragility e.g. for seismic fragility due to ageing effects (Torbol et al., 2013; Cheng et al., 2019). Therefore, the updated fragility $\left(t_{2}>t_{1}\right)$, can be expressed with an updated curve (dashed red) resulting in higher damage probability for the same intensity measure. If the asset model is updated based on the monitoring data, the median threshold 


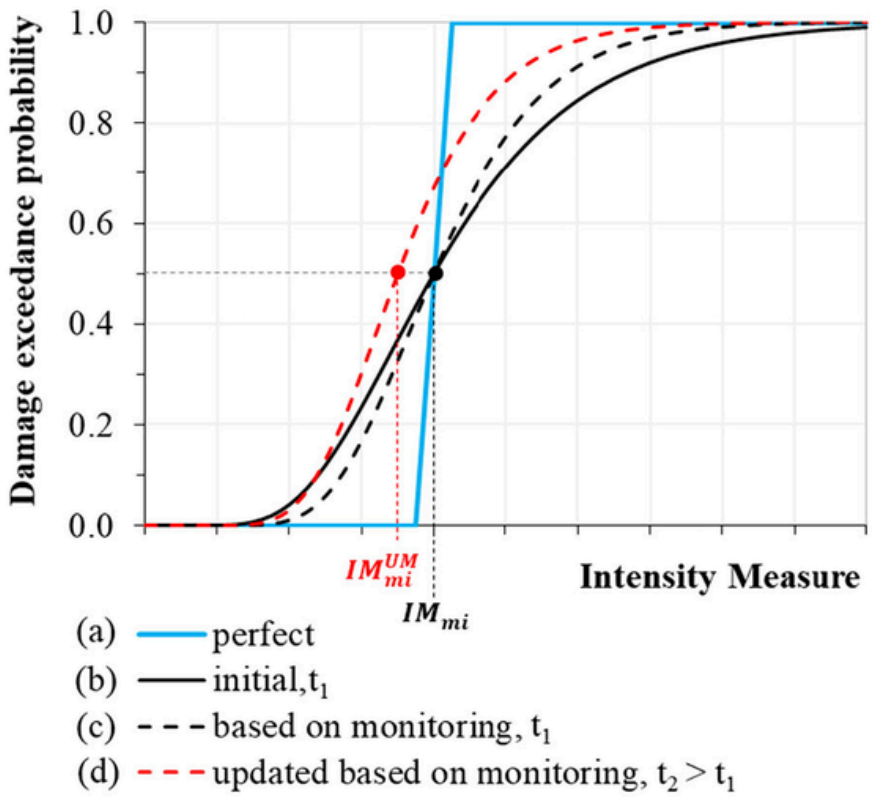

Fig. 6. Illustrative fragility functions: a) hypothetically perfect model with very low to zero uncertainty, b) initial model (theoretical uncertainty), c) initial model based on monitoring input (reduced uncertainty), d) model updated based on monitoring data and identification of defects.

value of the intensity measure required to cause the damage $\left(\mathrm{IM}_{\mathrm{mi}}\right)$ is expected to be shifted to the left $\left(\mathrm{IM}_{\mathrm{mi}}{ }^{\mathrm{UM}}\right)$. This means that the same damage level will occur for lower hazard intensity compared to the initial structure. As a result, the updated fragility models also reduce the uncertainty in resilience quantification, as reflected in Fig. 1a, b, d \&e (component and asset), i.e. quantification of loss of capacity due to external stressors at the time $t_{\text {dam }}$. Climate change projections will be taken into account in the hazard analysis, by deploying predictions for the future based on available models (Bertola et al., 2020; Blöschl et al., 2019). It is recognized that notwithstanding recent improvements on climate models, projections of changes in extremes remain uncertain. It is believed that monitoring can enable higher reliability, by providing almost real-time data for updating transport infrastructure models.

\subsection{Functionality and restoration}

Functionality loss models, which correlate, e.g. the reduction of traffic capacity for a given intensity measure, can measure indirect losses (Hackl et al., 2018) and can be facilitated or calibrated by monitoring data. For instance, closed-circuit television (CCTV) traffic cameras and drones can be used to identify the inundation depth, the extent and accumulation of debris flows/slumped mass, the extent of snow or icing, and the traffic conditions. These data can be used to correlate the functionality of the road with a hazard intensity measure, e.g. the standing water depth (Pregnolato et al., 2017) or the functionality loss due to an extreme event or accumulation of damage, see period M2 in Fig. 1I $\mathrm{a} \& \mathrm{~b}\left(t_{d a m}{ }^{I}\right)$. The rapidity of restoration is expressed through restoration models that quantify the percentage of the asset or network functionality, conditional on the damage state or the disruption, correspondingly. Well-informed restoration models are completely missing from the international literature for most of the natural and human-made hazards, whilst the ones that exist are limited solely to earthquake hazard events (Padgett and DesRoches, 2007; HAZUS MH, 2011; Gidaris et al., 2017; Mitoulis et al., 2019).

Traffic information extracted from Call Detail Record (CDR) crowd data or open-source (Lustenberger et al., 2019), e.g. Google maps and/or Waze, can provide input for the quantification of indirect losses, such as traffic delays, business interruption and environmental impacts, after the occurrence of a natural disaster (Kaiser et al., 2017). Traffic data provides evidence for the recovery process and can be used to improve/develop restoration models. These models can be updated with the use of satellite or UAV/Drone images to quantify the process of traffic recovery and/or the works of the restoration. Traffic and commute data or drivers' behaviours after a disaster can be detected and analysed using UAV and cameras (Salvo et al., 2017; Kim et al., 2019). The data-driven restoration models provide better estimation of the mitigation/recovery path in the resilience analysis of a component or network, which is represented by the red curves in Fig. 1I\&II (part M3). Therefore, the recovery period is shorter when monitoring is enabled $\left(t_{r e c}{ }^{M}\right)$, as opposed to the recovery without monitoring data $\left(t_{r e c}\right)$.

\subsection{Resilience-based asset management}

Instrumentation and sensors can provide real-time data for transport assets, including geotechnical assets, such as slope or embankment displacements and strains, groundwater conditions or lateral stresses on retaining structures (Srinivasan et al., 2010; Admassu et al., 2019). Hence, monitoring data can provide early-warnings for transport components or assets and improve the responsiveness of the operators, before reaching the critical level of capacity or functionality loss, as shown in Fig. 1 a, b \&c (time: $t_{\text {rec }}{ }^{M}, t_{\text {resp }}{ }^{M}$ ).

Aerial and satellite imagery is used for high-resolution measurements of displacements, lateral spreading, heaving and potholes, caused by floods, earthquakes and/or ground failures. These monitoring techniques may also facilitate the management of geotechnical assets, such as embankments, cuttings and natural slopes and support the decision-making by the network owners (Wolf et al., 2015; Pritchard et al., 2018). For instance, Herold and Roberts (2005) and Pan et al. (2018) detected ageing effects, potholes and cracks in roads pavements from airborne images, using artificial neural networks for data processing (Herold and Roberts, 2005; Pan et al., 2018). With these techniques, the tedious visual inspections are facilitated. Recently, UAVs have been integrated into post-disaster reconnaissance to document structural or geotechnical damage and collect data for the system during and after hazard events, such as earthquakes, floods and hurricanes (Pan et al., 2018; Murphy et al., 2016; Greenwood et al., 2019). UAV/Drone LiDAR are valuable and low-cost tools as they can access sites and provide information for efficient and rapid assessments of infrastructure even when a site is inaccessible. Comparison of pre- and post-disaster aerial imagery and UAV-acquired photogrammetric images can provide valuable evidence for the extent/type of damage in transport infrastructure. For instance, Valkaniotis et al. (2018) provided a detailed mapping of an earthquake-induced landslide in Lefkada, Greece, including the volume of the accumulated and removed material using drones (Zekkos et al., 2016). This information can also be utilised to evaluate the landslide susceptibility, and/or reactively, to estimate the size of the debris accumulation and their impact on the affected infrastructure, such as railways or highways. UAVs have been also integrated with the inspection and monitoring of bridges, to detect deformations and cracking (Polyfytos bridge, 2020'; Gillins et al., 2016; Ellenberg et al., 2014) and for developing 3D asset models (Khaloo et al., 2018). Such approaches can facilitate the recovery measures toward the adaptation of transport infrastructure to new conditions and demands, including the extension of their life-cycle (Fig. 1 c \& f, parts M2 and M3).

\section{Conclusions and future research pathways}

This paper delivers a unique roadmap, which integrates structural health and functionality monitoring (SHFM) data for enhancing risk and resilience evaluation, and thus enabling the efficient asset manage- 
ment and resource allocation in transport infrastructure. This research is in response to the ever-changing environment and the augmented requirements from the transport infrastructure networks, withstanding multiple hazards, exacerbated by climate changes, whilst ensuring minimal disruptions to underpin the economy and society. The key objective of the roadmap is to deliver time-efficiency and accuracy in resilience evaluations prior and after multiple hazards occurrences, including the periods of response, absorb of hazard or damage, recovery and adaptation after the disturbance.

An extended review and evaluation of SHFM methods and systems for transport infrastructure was conducted. The wide range of available solutions and technologies are presented for monitoring different stressors, in transport infrastructure assets and their direct and indirect contribution to resilience-based management. The importance of monitoring systems in enhancing the adaptation capacity of transport assets and networks is thoroughly discussed and demonstrated. It was found that the deployment of SHFM and digital technologies are vital for enhancing resilience because they achieve: (a) responsiveness, i.e. reduced post-damage lag time, (b) agile recovery and reinstatement of assets and networks, (c) increased reliability of asset condition data, and (d) capabilities for prompt adaptation. . In this respect, a set of novel resilience curves for components, assets and transport networks for cumulative damages and natural or human-induced hazards was introduced. These curves show that when monitoring systems are deployed, the uncertainties in data collection, for the risk assessment and resilience quantifications are mitigated. Thus, decision-makers are facilitated to timely choose efficient mitigation measures, based on reliable estimations of the condition of the network. This detailed knowledge is further fused in model updating for data-driven predictions of high reliability.

The roadmap also paves the way for utilising the monitoring data for the reliable quantification of the structural integrity, safety and functionality of the components, the asset and the network. These monitoring data, inclusive of data relevant to the environment and the external stressors, continuous recordings can then be deployed in reliable vulnerability and risk assessments. The accuracy of the chosen monitoring method and the sensitivity of the measurands to changes, influence the updated output of models, and thus, the predictions. This feedback significantly contributes to (a) the creation of accurate registries containing information of the exposure of the assets, (b) the reliable definition of the intensity and nature of hazards, (c) the more accurate definition of the damage probability for a given intensity measure, (d) the expedient restoration of the assets, (e) the efficient management of the assets, especially by delivering early warnings in extreme events and (f) the enhancement and adaptation of assets and networks to new requirements emanating from new loads and other climatic stressors.

In summary, all pointers are to digital technologies, which create new sets of data and enable different means to match multiple and inter-related types of information of significance to the resilience of transport infrastructure accurately. However, substantial interdisciplinary work and collaboration with the industrial world are required to exploit the potentials of these technologies and deploy them in management platforms, including coverage by design guidelines. The interdependences of different networks should also be explored, and resilience models should be developed based on performance indicators. The holistic approach forms the basis for shifting the mindset of modern approaches toward efficient design and management of transport networks tailored to sustainable, resilient services based on reliable monitoring data.

\section{Uncited references}

Cimellaro et al., 2016

Department for Transport, 2016

Dong et al., 2013
Esposito et al., 2020

Ganin et al., 2016

Gasparini et al., 2007

Gattulli et al., 2016

Guan et al., 2016

Hosseini et al., 2016

IAEA: International Atomic Energy Agency, 2018

Jáuregui et al., 2005

Luo, 1996

Miller et al., 2011

Ouyang and Wang, 2015

Sohn et al., 2011

St Leger et al., 2014

\section{Declaration of competing interest}

The authors declare that they have no known competing financial interests or personal relationships that could have appeared to influence the work reported in this paper.

\section{Acknowledgements}

This study has received funding by the European Commission H2020-Marie Skłodowska-Curie Research Grants Scheme MSCA-IF-2018 (grant agreement no 845549: BRIFACE- Novel assessment of bridge retrofitting measures through Interface Efficiency Indices (InterFeis) using a Guided Wave-based monitoring method). Dr. Sotirios A Argyroudis would like to acknowledge the support of the European Commission under the H2020-Marie Skłodowska-Curie Research Grants Scheme MSCA-IF-2016 (grant agreement No 746298: TRANSRISK-Vulnerability and risk assessment of transportation systems of assets exposed to geo-hazards).

\section{Appendix A.}

Table A.1

Measurands (1), techniques (2), types (3) and principles (4) in SHFM of infrastructure assets and deployment for informing directly (5) and indirectly (6) attributes and components of risk and resilience. 


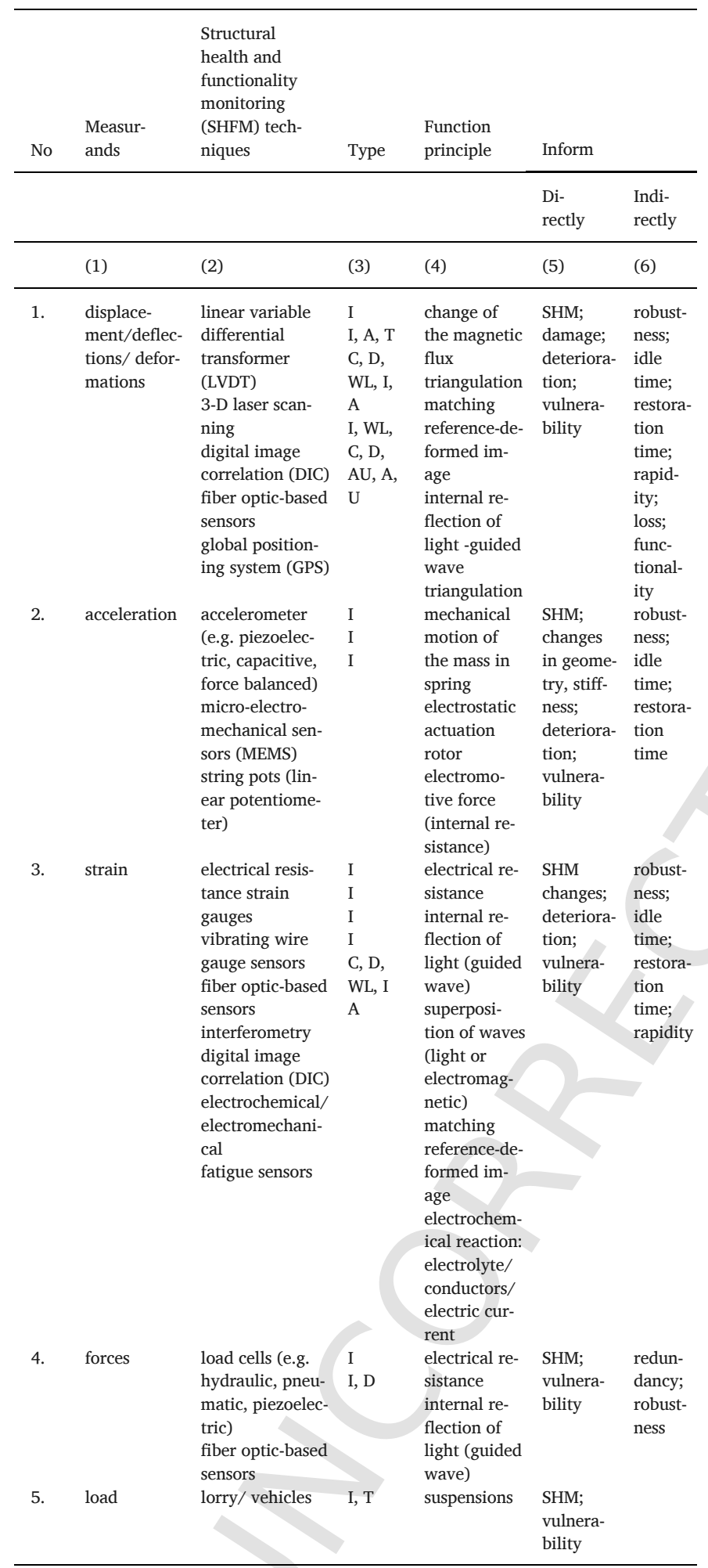

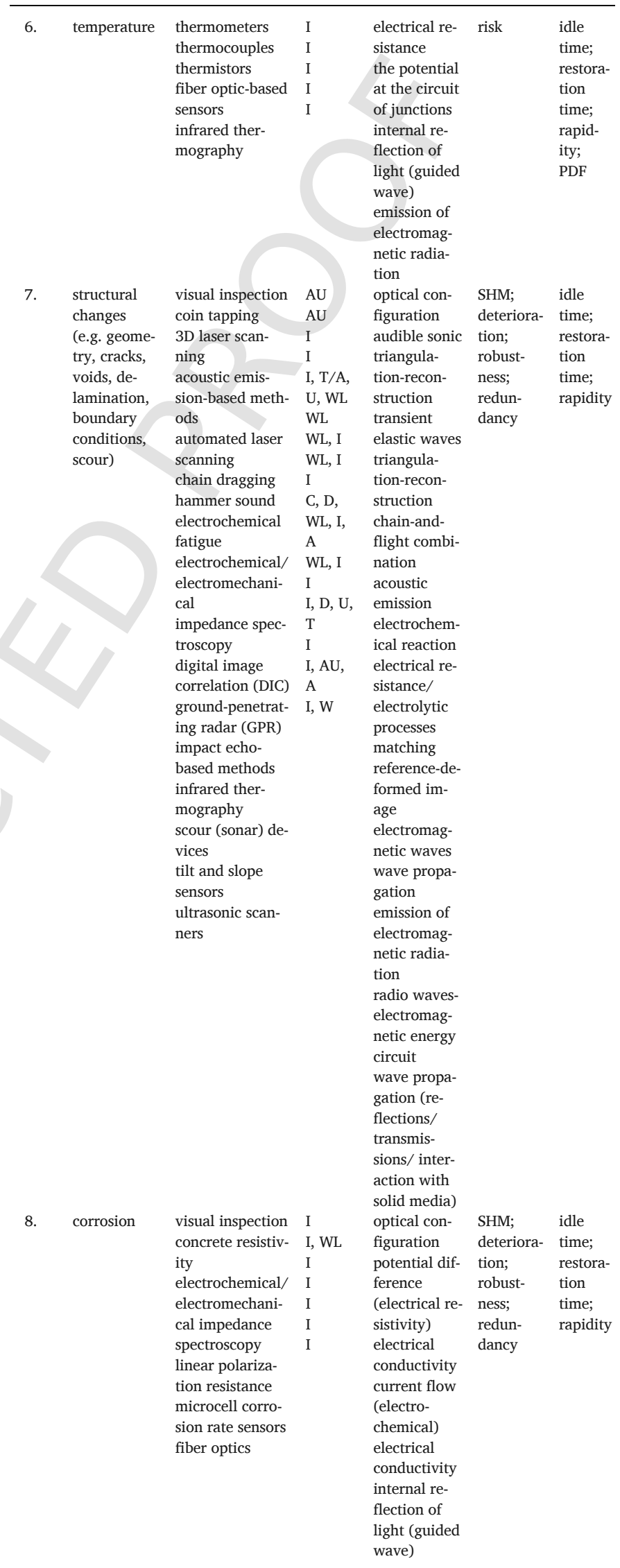




\begin{tabular}{|c|c|c|c|c|c|c|}
\hline 9. & $\begin{array}{l}\text { moisture/ } \\
\text { humidity/ } \\
\text { chlorides/ } \\
\text { air/water } \\
\text { pollution } \\
\text { wind } \\
\text { thunders }\end{array}$ & $\begin{array}{l}\text { visual inspection } \\
\text { moisture/chlo- } \\
\text { ride/ air/water } \\
\text { pollution content } \\
\text { sensors/ hy- } \\
\text { grometers/ } \\
\text { anemometers } \\
\text { (Hela et al., } \\
2005 \text { ) }\end{array}$ & $\begin{array}{l}\text { I, D, } \\
\text { WL, U, } \\
\text { A, T }\end{array}$ & $\begin{array}{l}\text { optical con- } \\
\text { figuration } \\
\text { colour mod- } \\
\text { ulation }\end{array}$ & $\begin{array}{l}\text { SHFM; } \\
\text { deteriora- } \\
\text { tion; } \\
\text { risk; } \\
\text { PDF }\end{array}$ & $\begin{array}{l}\text { func- } \\
\text { tional- } \\
\text { ity; } \\
\text { idle } \\
\text { time; } \\
\text { restora- } \\
\text { tion } \\
\text { time }\end{array}$ \\
\hline 10. & traffic & $\begin{array}{l}\text { cameras } \\
\text { satellites } \\
\text { drones } \\
\text { network of sta- } \\
\text { tions } \\
\text { crowd data } \\
\text { (open access) } \\
\text { (Seraj et al., } \\
\text { 2017; Kaiser et } \\
\text { al., 2017) }\end{array}$ & $\begin{array}{l}\text { I, C, D, } \\
\text { AU, U } \\
\text { I, C, D, } \\
\text { WL, } \\
\text { AU, U, } \\
\text { A } \\
\text { I, C, D, } \\
\text { WL, } \\
\text { AU, U, } \\
\text { A }\end{array}$ & $\begin{array}{l}\text { optical con- } \\
\text { figuration }\end{array}$ & $\begin{array}{l}\text { FM; } \\
\text { function- } \\
\text { ality; } \\
\text { risk; } \\
\text { idle time; } \\
\text { restora- } \\
\text { tion time }\end{array}$ & PDF \\
\hline 11. & $\begin{array}{l}\text { accumula- } \\
\text { tion of } \\
\text { snow/ wa- } \\
\text { ter/ debris }\end{array}$ & $\begin{array}{l}\text { cameras } \\
\text { satellites } \\
\text { drones } \\
\text { network of sta- } \\
\text { tions } \\
\text { crowd data } \\
\text { (open access) } \\
\text { (Seraj et al., } \\
\text { 2017; Kaiser et } \\
\text { al., 2017) }\end{array}$ & $\begin{array}{l}\text { I, C, D, } \\
\text { AU, U } \\
\text { I, C, D, } \\
\text { WL, } \\
\text { AU, U, } \\
\text { A } \\
\text { I, C, D, } \\
\text { WL, } \\
\text { AU, U, } \\
\text { A }\end{array}$ & & $\begin{array}{l}\text { FM; } \\
\text { risk; } \\
\text { idle time; } \\
\text { restora- } \\
\text { tion time }\end{array}$ & $\begin{array}{l}\text { PDF; } \\
\text { vulnera- } \\
\text { bility }\end{array}$ \\
\hline
\end{tabular}

Type: Contactless (C), Distant (D), Wireless (WL), Instrumented (I), Autonomous (AU), Unattended (U), Aerial (A), Terrestrial (T)

\section{Table A.2}

Monitoring techniques of non-destructive testing (NDT) (1), advantages (2), disadvantages (3) and cost (4), toward the assessment and quantification of risk and resilience attributes (5).

\begin{tabular}{|c|c|c|c|c|c|}
\hline No & $\begin{array}{l}\text { Struc- } \\
\text { tural } \\
\text { health } \\
\text { and } \\
\text { func- } \\
\text { tional- } \\
\text { ity } \\
\text { moni- } \\
\text { toring } \\
\text { (SHFM) } \\
\text { tech- } \\
\text { niques }\end{array}$ & Advantages & Disadvantages & $\begin{array}{l}\text { Cost } \\
\text { includ- } \\
\text { ing re- } \\
\text { sources }\end{array}$ & $\begin{array}{l}\text { Assess- } \\
\text { ment/ } \\
\text { quantific } \\
\text { tion of }\end{array}$ \\
\hline & (1) & (2) & (3) & (4) & (5) \\
\hline 1. & $\begin{array}{l}\text { visual in- } \\
\text { spections }\end{array}$ & $\begin{array}{l}\text { - rapid } \\
\text { - inexpensive }\end{array}$ & $\begin{array}{l}\text { - only accessible } \\
\text { areas } \\
\text { - } \text { superficial dam- } \\
\text { ages only } \\
\text { - } \text { time-consuming } \\
\text { to evaluate re- } \\
\text { sults } \\
\text { - experienced sur- }\end{array}$ & low & $\begin{array}{l}\text { damage; } \\
\text { deterior: } \\
\text { structure } \\
\text { modifica } \\
\text { tions; } \\
\text { vulnerab } \\
\text { function } \\
\text { obstructi }\end{array}$ \\
\hline 2. & $\begin{array}{l}\text { coin tap } \\
\text { test }\end{array}$ & $\begin{array}{l}\text { no training or } \\
\text { specialisation } \\
\text { equipment } \\
\text { needed }\end{array}$ & $\begin{array}{l}\text { - low accuracy } \\
\text { - subjective } \\
\text { - experienced sur- } \\
\text { veyor needed }\end{array}$ & low & deterior: \\
\hline 3. & $\begin{array}{l}\text { chain } \\
\text { dragging }\end{array}$ & $\begin{array}{l}\text { - easy to apply } \\
\text { (STM D } \\
\text { 4580-861,992) }\end{array}$ & $\begin{array}{l}\text { subjective and } \\
\text { dependent on } \\
\text { the inspector's } \\
\text { experience } \\
\text { (Scott et al., } \\
\text { 2003) } \\
\text { - disruption of } \\
\text { function }\end{array}$ & low & deterior: \\
\hline
\end{tabular}

\begin{tabular}{|c|c|c|c|c|c|}
\hline 4. & $\begin{array}{l}\text { laser } \\
\text { scanning } \\
\text { systems }\end{array}$ & $\begin{array}{l}\text { precision } \\
\text { (Riveiro et al., } \\
2013 ; \text { Park et } \\
\text { al., 2007) } \\
\text { - global survey } \\
\text { and point cloud } \\
\text { of the asset }\end{array}$ & $\begin{array}{l}\text { reduced accuracy due } \\
\text { to (González-Aguil- } \\
\text { era et al., 2008; } \\
\text { Cygas and } \\
\text { Froehner, 2008): } \\
\text { - climatic condi- } \\
\text { tions } \\
\text { - distance from } \\
\text { the asset } \\
\text { - different materi- } \\
\text { als and surfaces } \\
\text { - measures the } \\
\text { different orien- } \\
\text { tation of the } \\
\text { structure }\end{array}$ & moderate & $\begin{array}{l}\text { structure } \\
\text { changes; } \\
\text { deteriore } \\
\text { vulnerab }\end{array}$ \\
\hline 5. & $\begin{array}{l}\text { ac- } \\
\text { celerome- } \\
\text { ters }\end{array}$ & $\begin{array}{l}\text { - time history of } \\
\text { response } \\
\text { - durable over } \\
\text { time } \\
\text { - little depen- } \\
\text { dency on the } \\
\text { traffic loads } \\
\text { (Ngamkhanong } \\
\text { et al., 2018) }\end{array}$ & $\begin{array}{l}\text { - errors due to nu- } \\
\text { merical integra- } \\
\text { tion } \\
\text { - large amount of } \\
\text { data } \\
\text { - intensive post- } \\
\text { processing } \\
\text { - amplification is } \\
\text { needed } \\
\text { (Ngamkhanong } \\
\text { et al., 2018) }\end{array}$ & moderate & $\begin{array}{l}\text { Damage; } \\
\text { structure } \\
\text { changes; } \\
\text { deteriorc } \\
\text { vulnerab } \\
\text { redundar }\end{array}$ \\
\hline 6. & $\begin{array}{l}\text { fiber op- } \\
\text { tics }\end{array}$ & $\begin{array}{l}\text { - measures two } \\
\text { points in one } \\
\text { time and the dis- } \\
\text { tributed configu- } \\
\text { ration } \\
\text { - multiple mea- } \\
\text { surements } \\
\text { - diverse types of } \\
\text { measurements } \\
\text { (e.g. tempera- } \\
\text { ture, strains, } \\
\text { stresses) (Ye et } \\
\text { al., 2014) } \\
\text { - wide dynamic } \\
\text { range } \\
\text { - immune to elec- } \\
\text { tromagnetic in- } \\
\text { terference } \\
\text { - dependent on } \\
\text { different tech- } \\
\text { niques \& princi- } \\
\text { ples (Antunes } \\
\text { et al., 2012) }\end{array}$ & $\begin{array}{l}\text { - sensitive to ther- } \\
\text { mal difference/ } \\
\text { temperature } \\
\text { (Barrias et al., } \\
\text { 2016) } \\
\text { - sensitivity in in- } \\
\text { stallation } \\
\text { - challenging to } \\
\text { decompose } \\
\text { wavelengths of } \\
\text { different mea- } \\
\text { surements }\end{array}$ & moderate & $\begin{array}{l}\text { structura } \\
\text { changes; } \\
\text { deteriore } \\
\text { vulnerab }\end{array}$ \\
\hline 7. & $\begin{array}{l}\text { laser sta- } \\
\text { tion }\end{array}$ & $\begin{array}{l}\text { measures nodes } \\
\text { coordinates } \\
\text { conversion to } \\
\text { coordinates } \\
\text { - speed of mea- } \\
\text { surement } \\
\text { - capturing data } \\
\text { related to dis- } \\
\text { tance (range), } \\
\text { intensity, and } \\
\text { colour (Ran- } \\
\text { dall, 2011) }\end{array}$ & $\begin{array}{l}\text { no dynamic } \\
\text { measurements } \\
\text { accuracy de- } \\
\text { pends on the sta- } \\
\text { bility of the sta- } \\
\text { tion }\end{array}$ & high & $\begin{array}{l}\text { changes } \\
\text { positions } \\
\text { deterior } \\
\text { risk; } \\
\text { PDF }\end{array}$ \\
\hline
\end{tabular}




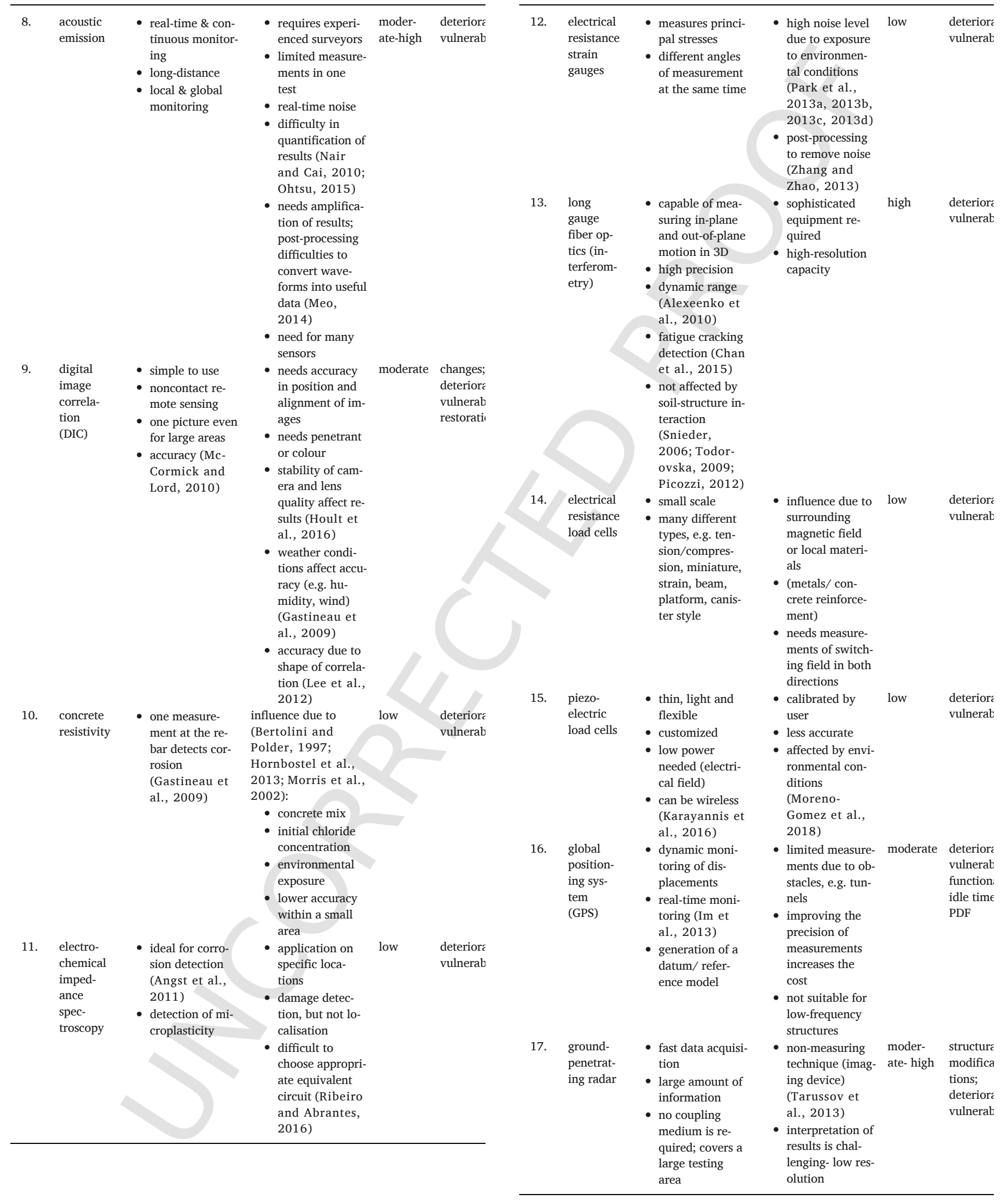




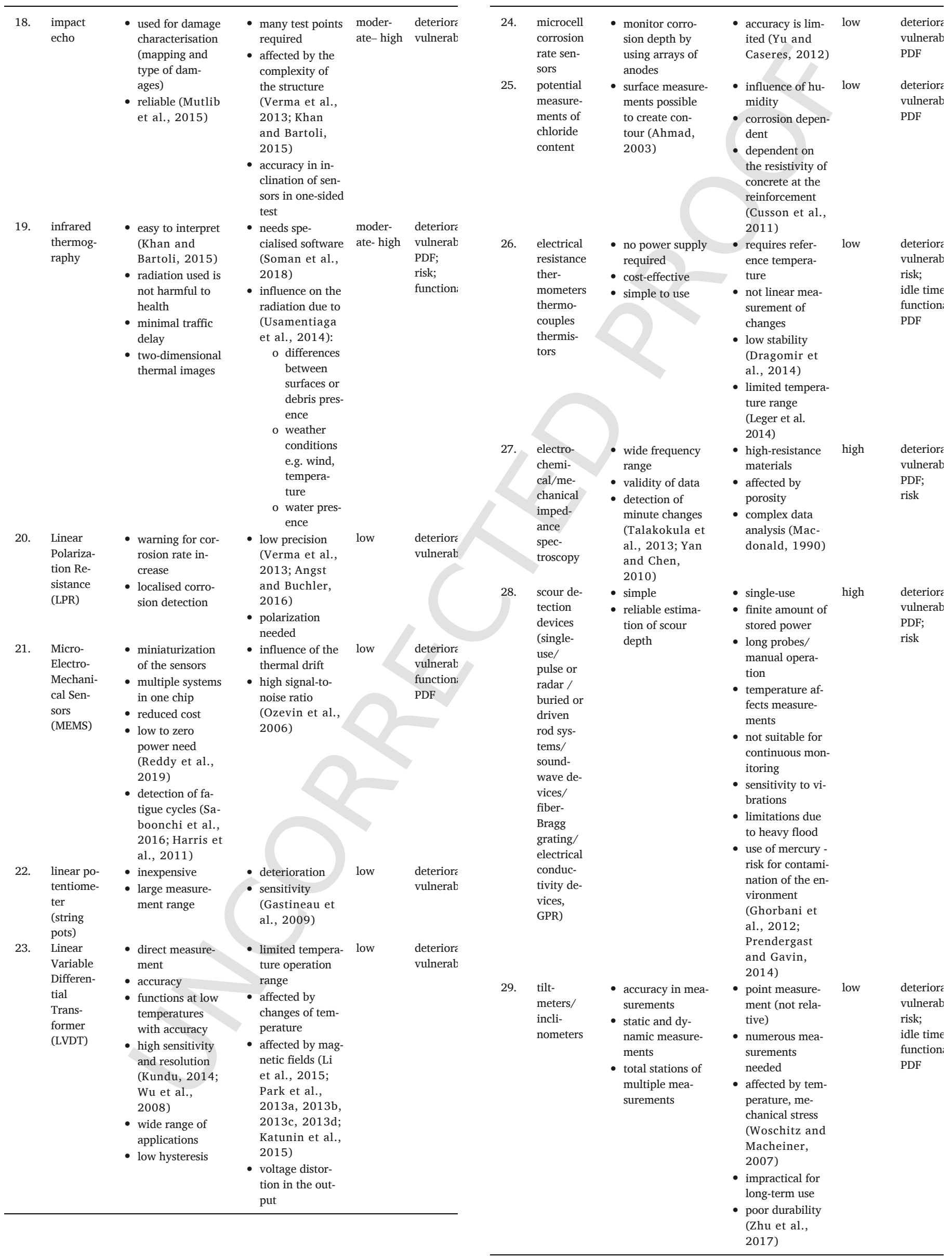




\begin{tabular}{|c|c|c|c|c|c|}
\hline 30. & $\begin{array}{l}\text { ultrasonic } \\
\text { C-scan } \\
\text { imaging }\end{array}$ & $\begin{array}{l}\text { - detects both cor- } \\
\text { rosion and voids } \\
\text { in a single test } \\
\text { (Iyer et al., } \\
\text { 2005) } \\
\text { - damage charac- } \\
\text { terisation and } \\
\text { mapping tech- } \\
\text { nique (Katunin } \\
\text { et al., 2015) }\end{array}$ & $\begin{array}{l}\text { the interpreta- } \\
\text { tion of data is } \\
\text { challenging } \\
\text { (Kundu, 2014) }\end{array}$ & moderate & $\begin{array}{l}\text { deteriorc } \\
\text { vulnerab } \\
\text { robustne }\end{array}$ \\
\hline 31. & $\begin{array}{l}\text { vibrating } \\
\text { wire } \\
\text { strain } \\
\text { gauges }\end{array}$ & $\begin{array}{l}\text { - accurate mea- } \\
\text { surements over } \\
\text { time } \\
\text { - immune to elec- } \\
\text { tromagnetic in- } \\
\text { terference } \\
\text { - superior durabil- } \\
\text { ity } \\
\text { - easy installation } \\
\text { (Park et al., } \\
\text { 2013a, 2013b, } \\
\text { 2013c, 2013d) }\end{array}$ & $\begin{array}{l}\text { - need to account } \\
\text { for gauge factor } \\
\text { for accuracy } \\
\text { - influence of tem- } \\
\text { perature- un- } \\
\text { equal strains in } \\
\text { the medium } \\
\text { (Park et al., } \\
2013 a, 2013 b \text {, } \\
\text { 2013c, 2013d) }\end{array}$ & low & $\begin{array}{l}\text { deteriore } \\
\text { vulnerab } \\
\text { robustne }\end{array}$ \\
\hline 32. & $\begin{array}{l}\text { moisture/ } \\
\text { chloride/ } \\
\text { air pollu- } \\
\text { tion con- } \\
\text { tent sen- } \\
\text { sors }\end{array}$ & $\begin{array}{l}\text { - } \text { simple use } \\
\text { - }\end{array}$ & $\begin{array}{l}\text { - affected by } \\
\text { structure age } \\
\text { - affected by } \\
\text { crack width un- } \\
\text { der immersion } \\
\text { (Ye et al., } \\
2013 \text { ) }\end{array}$ & low & $\begin{array}{l}\text { deteriore } \\
\text { vulnerab } \\
\text { PDF; } \\
\text { risk }\end{array}$ \\
\hline 33. & $\begin{array}{l}\text { un- } \\
\text { manned } \\
\text { airborne } \\
\text { visual in- } \\
\text { spections- } \\
\text { measure- } \\
\text { ments- } \\
\text { data col- } \\
\text { lection } \\
\text { (drones/ } \\
\text { cameras/ } \\
\text { satellite } \\
\text { images) }\end{array}$ & $\begin{array}{l}\text { - distant measure- } \\
\text { ments } \\
\text { - applications in } \\
\text { inaccessible } \\
\text { sites, e.g. after a } \\
\text { disaster } \\
\text { - cost-efficiency } \\
\text { - continuous mea- } \\
\text { surement }\end{array}$ & $\begin{array}{l}\text { - } \text { accuracy } \\
\text { - human guidance } \\
\text { (Greenwood et } \\
\text { al., 2019) }\end{array}$ & moderate & $\begin{array}{l}\text { deteriore } \\
\text { vulnerab } \\
\text { PDF; } \\
\text { risk; } \\
\text { function: } \\
\text { idle time }\end{array}$ \\
\hline
\end{tabular}

\section{References}

AASHTO, 1998. AASHTO Guide for Commonly Recognized (CoRe) Structural Elements. 1st ed. (Washington, D.C).

AASHTO, 2000. Manual for Condition Evaluation of Bridges. 2nd ed. (Washington, D.C).

AASHTO, 2017. AASHTO LRFD Bridge Design Specifications. 8th ed. American Association of State Highway and Transportation Officials, Washington, DC.

Abdelgawad, A, Yelamarthi, K, 2017. Internet of things (IoT) platform for structure health monitoring. Wirel. Commun. Mob. Comput. 2017.

Abdeljaber, O, Avci, O, Kiranyaz, S, Gabbouj, M, Inman, D J, 2017. Real-time vibration-based structural damage detection using one-dimensional convolutional neural networks. J. Sound Vib. 388, 154-170.

Achillopoulou, D V, Pau, A, 2017. Characterization of defects in plates using shear and Lamb waves. Procedia Engineering 199, 2001-2007.

Acton, S, 2016. InSAR Remote Sensing for Performance Monitoring of Transportation Infrastructure at the Network Level.

ADB What does climate change mean for Asia's future infrastructure?Article onlineAsian Development Bankhttps://www.adb.org/news/features/what-does-climate-changemean-asia-s-future-infrastructure2017(accessed January 2020)

Admassu, K A, Lynch, J P, Athanasopoulos-Zekkos, A, Zekkos, D, 2019. Long-term wireless monitoring solution for the risk management of highway retaining walls. In: Nondestructive Characterization and Monitoring of Advanced Materials, Aerospace, Civil Infrastructure, and Transportation XIII, 10971. International Society for Optics and Photonics, p. 1097103.

Ahmad, S, 2003. Reinforcement corrosion in concrete structures, its monitoring and service life prediction - a review. Cem. Concr. Compos. 25 (4-5), 459-471.

Alavi, A H, Hasni, H, Lajnef, N, Chatti, K, Faridazar, F, 2016. An intelligent structural damage detection approach based on self-powered wireless sensor data. Autom. Constr. 62, 24-44.

Alexeenko, I, Vandenrijt, J, Georges, M, Pedrini, G, Cédric, T, Osten, W, Vollheim, B, 2010. Digital holographic interferometry by using long wave infrared radiation (CO2 laser). Appl. Mech. Mater. 24-25, 147-152.

Alkayem, N F, Cao, M, Zhang, Y, Bayat, M, Su, Z, 2018. Structural damage detection using finite element model updating with evolutionary algorithms: a survey. Neural Comput. \& Applic. 30 (2), 389-411.
Almufti, I, Willford, M, 2013. REDi: Rating System Resilience-based Earthquake Design Initiative for the Next Generation of Buildings. Arup.

Angst, U.M. and Buchler, M. 2016. Corrosion rate measurements in concrete- a closer look at the linear polarization resistance method. In: Concrete Repair, Rehabilitation and Retrofitting IV. London: Taylor \& Francis Group-Dehn et al. (Eds), pp.198-199.

Angst, U M, Elsener, B, Larsen, C K, Vennesland, Ø, 2011. Chloride induced reinforcement corrosion: electrochemical monitoring of initiation stage and chloride threshold values. Corros. Sci. 53 (4), 1451-1464 ISSN 0010-938X. https://doi.org/10.1016/j. corsci.2011.01.025.

Antunes, P, Lima, H, Varum, H, André, P, 2012. Optical fiber sensors for static and dynamic health monitoring of civil engineering infrastructures: abode wall case study. Measurement 45 (7), 1695-1705.

Argyroudis, S, Kaynia, A M, 2014. Fragility functions of highway and railway infrastructure. In: Pitilakis, K, Crowley, H, Kaynia, A M (Eds.), SYNER-G: Typology Definition and Fragility Functions for Physical Elements at Seismic Risk. GGEE 27. Springer.

Argyroudis, S A, Mitoulis, SA, Winter, M G, Kaynia, A M, 2019. Fragility of transport assets exposed to multiple hazards: state-of-the-art review toward infrastructural resilience. Reliability Engineering \& System Safety 191, 106567.

Argyroudis, S A, Mitoulis, S A, Hofer, L, Zanini, M A, Tubaldi, E, Frangopol, D M, 2020. Resilience assessment framework for critical infrastructure in a multi-hazard environment: case study on transport assets. Sci. Total Environ.. doi:10.1016/ j.scitotenv.2020.136854.

ASCE: American Society of Civil Engineers Infrastructure report card: a comprehensive assessment of America's infrastructure[online] Available athttps://www. infrastructurereportcard.org/wp-content/uploads/2019/02/Full-2017-Report-CardFINAL.pdf20175 October 2019

ASTM D 4580-86, 1992. Annual book of ASTM standards (1992). In: Standard Practice for Measuring Delaminations in Concrete Bridge Decks by Sounding. American Standards for Testing Materials.

Ayyub, B M, 2014. Systems resilience for multihazard environments: definition, metrics, and valuation for decision making. Risk Anal. 34 (2), 340-355.

Azimi, M, Eslamlou, A D, Pekcan, G, 2020. Data-driven structural health monitoring and damage detection through deep learning: state-of-the-art review. Sensors 20 (10), 2778.

Barrias, A, Casas, J, Villalba, S, 2016. A review of distributed optical fiber sensors for civil engineering applications. Sensors 16 (5), 748.

Behnia, A, Chai, H, Shiotani, T, 2014. Advanced structural health monitoring of concrete structures with the aid of acoustic emission. Constr. Build. Mater. 65, 282-302.

Bertola, M, Viglione, A, Lun, D, Hall, J, Blöschl, G, 2020. Flood trends in Europe: are changes in small and big floods different? Hydrology \& Earth System Sciences 1 (4), 24.

Bertolini, L, Polder, R B, 1997. TNO Report - Concrete Resistivity and Reinforcement Corrosion Rate as a Function of Temperature and Humidity of the Environment. TNO Building and Construction Research.

Billah, A H M, Alam, M S, 2015. Seismic fragility assessment of highway bridges: a state-of-the-art review. Struct. Infrastruct. Eng. 11 (6), 804-832.

Bindi, D, Boxberger, T, Orunbaev, S, Pilz, M, Stankiewicz, J, Pittore, M, Iervolino, I, Ellguth, E, Parolai, S, 2015. On-site early-warning system for Bishkek (Kyrgyzstan). Ann. Geophys. 58 (1)

Blöschl, G, Hall, J, Viglione, A, Perdigão, R A, Parajka, J, Merz, B, Lun, D, Arheimer, B, Aronica, G T, Bilibashi, A, Boháč, M, 2019. Changing climate both increases and decreases European river floods. Nature 573 (7772), 108-111.

Bruno, S, De Fino, M, Fatiguso, F, 2018. Historic building information modelling: performance assessment for diagnosis-aided information modelling and management. Autom. Constr. 86, 256-276.

Bruns, M, Hofmeister, B, Grießmann, T, Rolfes, R, 2019. Comparative Study of Parameterizations for Damage Localization with Finite Element Model Updating.

Chan, H, Masserey, B, Fromme, P, 2015. High frequency guided ultrasonic waves for hidden fatigue crack growth monitoring in multi-layer model aerospace structures. Smart Mater. Struct. 24 (2), 025037.

Chang, F K (Ed.), 2013. Structural Health Monitoring 2013: A Roadmap to Intelligen Structures: Proceedings of the Ninth International Workshop on Structural Health Monitoring, September 10-12, 2013. DEStech Publications, Inc.

Chatzi, E N, Spiridonakos, M D, 2015. Structural identification and monitoring based on uncertain/limited information. In: MATEC Web of Conferences, 24. EDP Sciences, p. 1003.

Chatzis, M N, Chatzi, E N, Smyth, A W, 2015. An experimental validation of time domain system identification methods with fusion of heterogeneous data. Earthquake Engineering \& Structural Dynamics 44 (4), 523-547.

Chen, H P, 2018. Structural Health Monitoring of Large Civil Engineering Structures. John Wiley \& Sons.

Cheng, Y, Zhang, J, Wu, J, 2019. Fragility analysis of a self-anchored suspension bridge based on structural health monitoring data. Advances in Civil Engineering 7467920. doi:10.1155/2019/7467920

Chkrebtii, O A, Campbell, D A, Calderhead, B, Girolami, M A, 2016. Bayesian solution uncertainty quantification for differential equations. Bayesian Anal. 11 (4), 1239-1267.

Cimellaro, G P, Renschler, C, Reinhorn, A M, Arendt, L, 2016. PEOPLES: a framework for evaluating resilience. J. Struct. Eng. 142 (10), 04016063.

Connelly, E B, Allen, C R, Hatfield, K, Palma-Oliveira, J M, Woods, D D, Linkov, I, 2017. Features of resilience. Environment systems and decisions 37 (1), 46-50.

Coxon, G, Freer, J, Westerberg, I K, Wagener, T, Woods, R, Smith, P J, 2015. A novel framework for discharge uncertainty quantification applied to 500 UK gauging stations. Water Resour. Res. 51 (7), 5531-5546. 
Crotti, G, Cigada, A, 2019. Scour at river bridge piers: real-time vulnerability assessment through the continuous monitoring of a bridge over the river Po, Italy. J. Civ. Struct. Heal. Monit. 9 (4), 513-528.

Cusson, D, Lounis, Z, Daigle, L, 2011. Durability monitoring for improved service life predictions of concrete bridge decks in corrosive environments. Computer-Aided Civil and Infrastructure Engineering 26 (7), 524-541.

Cygas, D, Froehner, K, 2008. Metrological aspects in terrestrial laser scanning technology. In: 7th International Conference Environmental Engineering. VGTU Press, Vilnius, pp. 1514-1518.

Dawson, R J, Thompson, D, Johns, D, Gosling, S, Chapman, L, Darch, G, Watson, G, Powrie, W, Bell, S, Paulson, K, Hughes, P, Wood, R, 2016. UK Climate Change Risk Assessment Evidence Report: Chapter 4, Infrastructure. Report Prepared for the Adaptation Sub-Committee of the Committee on Climate Change, London.

Department for Transport, 2016. Road Use Statistics Great Britain 2016. GOV.UK.

Dong, Y, Frangopol, D M, 2016. Probabilistic time-dependent multihazard life-cycle assessment and resilience of bridges considering climate change. J. Perform. Constr. Facil. 30 (5), 04016034.

Dong, Y, Frangopol, D, Saydam, D, 2013. Time-variant sustainability assessment of seismically vulnerable bridges subjected to multiple hazards. Earthquake Engineering \& Structural Dynamics 42 (10), 1451-1467.

Dottori, F, Salamon, P, Bianchi, A, Alfieri, L, Hirpa, F A, Feyen, L, 2016. Development and evaluation of a framework for global flood hazard mapping. Adv. Water Resour. 94, 87-102.

Dowds, J, Aultman-Hall, L, 2015. Barriers to implementation of climate adaptation frameworks by state departments of transportation. Transp. Res. Rec. 2532 (1), 21-28.

Dragomir, A, Adam, M, Andruşcă, M, Molodeschi, M, Pantelimon, R, 2014. About thermal stresses monitoring and diagnosis of electrical equipment. In: International Conference and Exposition on Electrical and Power Engineering (EPE 2014).

Ehrlich, D, Tenerelli, P, 2013. Optical satellite imagery for quantifying spatio-temporal dimension of physical exposure in disaster risk assessments. Nat. Hazards 68 (3), 1271-1289.

Ellenberg, A, Branco, L, Krick, A, Bartoli, I, Kontsos, A, 2014. Use of unmanned aerial vehicle for quantitative infrastructure evaluation. J. Infrastruct. Syst. 21 (3), 4014054.

EN 1998-2 Eurocode 8, 2005. Design of Structures for Earthquake Resistance. Part 2: Bridges. European Committee for Standardization, Brussels, Belgium.

Eschmann, C, Wundsam, T, 2017. Web-based georeferenced 3D inspection and monitoring of bridges with unmanned aircraft systems. J. Surv. Eng. 143 (3), 04017003.

Esposito, S, Stojadinović, B, Babič, A, Dolšek, M, Iqbal, S, Selva, J, Giardini, D, 2020. Risk-based multilevel methodology to stress test critical infrastructure systems. J. Infrastruct. Syst. 26 (1), 04019035.

European Union Road Federation ROAD STATISTICS-YEARBOOK[online] Brussels. Available athttp://www.erf.be/wp-content/uploads/2018/01/Road_statistics_2017. pdf20175 October 2019

Fabozzi, S, Bilotta, E, Picozzi, M, Zollo, A, 2018. Feasibility study of a loss-driven earthquake early warning and rapid response systems for tunnels of the Italian high-speed railway network. Soil Dyn. Earthq. Eng. 112, 232-242.

Farrar, C R, Worden, K, 2012. Structural Health Monitoring.: A Machine Learning Perspective. John Wiley \& Sons.

FEMA: Federal Emergency Management Agency (US), 2017. Rapid Visual Screening of Buildings for Potential Seismic Hazards: A Handbook. Government Printing Office.

FHWA Risk-based transportation asset management: building resilience into transportation assets. Report 5: managing external threats through risk-based asset managementMarch, Available atUS Department of Transportation, Federal Highway Administrationhttps://www.fhwa.dot.gov/asset/pubs/hif13018.pdf2013

FHWA, 2014. System Preparedness and Resilience to Climate Change and Extreme Weather Events. FHWA Order 5520. Federal Highway Administration, U.S. Department of Transportation, p. 2014.

Forzieri, G, Bianchi, A, e Silva, F B, Herrera, M A M, Leblois, A, Lavalle, C, Aerts, J C J $\mathrm{H}$, Feyen, L, 2018. Escalating impacts of climate extremes on critical infrastructures in Europe. Glob. Environ. Chang. 48, 97-107.

Franchin, P, 2018. Research needs towards a resilient community. In: Pitilakis, K (Ed.), Recent Advances in Earthquake Engineering in Europe. ECEE 2018. Geotechnical, Geological and Earthquake Engineering, vol 46. Springer, Cham.

Frangopol, D M, Bocchini, P, 2011. Resilience as optimization criterion for the bridge rehabilitation of a transportation network subject to earthquake. In: D. Ames, D, Droessler, T L, M. Hoit, M (Eds.), ASCE Structures Congress 2011. ASCE, CD-ROM, pp. 2044-2055.

Friswell, M, Mottershead, J E, 2013. Finite Element Model Updating in Structural Dynamics. 38. Springer Science \& Business Media.

Fujino, Y, Siringoringo, D, 2011. Bridge monitoring in Japan: the needs and strategies. Struct. Infrastruct. Eng. 7 (7-8), 597-611.

Fujino, Y, Siringoringo, D M, Ikeda, Y, Nagayama, T, Mizutani, T, 2019. Research and implementations of structural monitoring for Bridges and buildings in Japan. Engineering 5 (6), 1093-1119.

Galaitsi, S, Trump, B D, Keisler, J M, Linkov, I, 2019. The Need to Reconcile Concepts that Characterize Systems Withstanding Threats. arXiv preprint arXiv:1912.10457.

Ganin, A A, Massaro, E, Gutfraind, A, Steen, N, Keisler, J M, Kott, A, Mangoubi, R, Linkov, I, 2016. Operational resilience: concepts, design and analysis. Sci. Rep. 6 (1), 1-12.

Ganin, A A, Kitsak, M, Marchese, D, Keisler, J M, Seager, T, Linkov, I, 2017. Resilience and efficiency in transportation networks. Sci. Adv. 3 (12), e1701079.
Ganin, A A, Mersky, A C, Jin, A S, Kitsak, M, Keisler, J M, Linkov, I, 2019. Resilience in intelligent transportation systems (ITS). Transportation Research Part C: Emerging Technologies 100, 318-329.

Gasparini, P, Manfredi, G, Zschau, J, 2007. Earthquake Early Warning Systems. Springer-Verlag, Berlin Heidelberg. doi:10.1007/978-3-540-72241-0.

Gastineau, A, Johnson, T, Schultz, A, 2009. Bridge Health Monitoring and Inspections Systems -A Survey of Methods, Technical Report. Department of Civil Engineering University of Minnesota, Minnesota Department of Transportation.

Gattulli, V, Lepidi, M, Potenza, F, 2016. Dynamic testing and health monitoring of historic and modern civil structures in Italy. Structural Monitoring and Maintenance 3 (1), 71-90.

Ghorbani, M, Sharifzadeh, M, Yasrobi, S, Daiyan, M, 2012. Geotechnical, structural and geodetic measurements for conventional tunnelling hazards in urban areas - the case of Niayesh road tunnel project. Tunn. Undergr. Space Technol. 31, 1-8 ISSN 0886-7798. https://doi.org/10.1016/j.tust.2012.02.009.

Gidaris, I, Padgett, J E, Barbosa, A R, Chen, S, Cox, D, Webb, B, Cerato, A, 2017 Multiple-hazard fragility and restoration models of highway bridges for regional risk and resilience assessment in the United States: state-of-the-art review. J. Struct. Eng. 143 (3).

Gil, J, 2015. Building a multimodal urban network model using OpenStreetMap data for the analysis of sustainable accessibility. In: OpenStreetMap in GIScience: Experiences, Research, Applications. Springer, pp. 229-251.

Gillins, M N, Gillins, D T, Parrish, C, 2016. Cost-effective bridge safety inspections using unmanned aircraft systems (UAS). In: Proc., Geotechnical and Structural Engineering Congress 2016. ASCE, Reston, VA, pp. 1931-1940.

Gkoumas, K, Marques Dos Santos, F L, van Balen, M, Tsakalidis, A, Ortega Hortelano, A, Grosso, M, Pekár, F, 2019. Research and Innovation in Bridge Maintenance, Inspection and Monitoring (No. JRC115319).

González-Aguilera, D, Gómez-Lahoz, J, Sánchez, J, 2008. A new approach for structural monitoring of large dams with a three-dimensional laser scanner. Sensors 8 (9), $5866-5883$.

Grasso, D, Burkins, M B, 2010. Beyond technology: the holistic advantage. In: Holistic Engineering Education. Springer, New York, NY, pp. 1-10.

Greenwood, W W, Lynch, J P, Zekkos, D, 2019. Applications of UAVs in civil infrastructure. J. Infrastruct. Syst. 25 (2), 04019002.

Guan, H, Li, J, Cao, S, Yu, Y, 2016. Use of mobile LiDAR in road information inventory: a review. Int. J. Image Data Fusion 7 (3), 219-242.

Guthrie, P, O'Hanlon, F, MacAskill, K, 2019. Advanced city-scale modelling and simulations for infrastructure resilience. In: Resilience Shift Roundtable Series. Cambridge University and Resilience Shift, UK.

Hackl, J, Lam, J C, Heitzler, M, Adey, B T, Hurni, L, 2018. Estimating network related risks: a methodology and an application in the transport sector. Nat. Hazards Earth Syst. Sci. 18, 2273-2293.

Hallegatte, S, Rozenberg, J, Rentschler, J, Nicolas, C, Fox, C, 2019. Strengthening new infrastructure assets: a cost-benefit analysis. In: Lifelines: The Resilient Infrastructure Opportunity, the World Bank: Climate Change Group Global Facility for Disaster Reduction and Recovery.

Harris, A, Oppenheim, I, Greve, D, 2011. MEMS-based high-frequency vibration sensors. Smart Mater. Struct. 20 (7), 075018.

Havaei-Ahary, B, 2018. Road Traffic Estimates: Great Britain 2017. Department for Transport, GOV.UK.

HAZUS-MH, 2011. Multi-Hazard Loss Estimation Methodology: Earthquake Model Hazus-MH MR5 Technical Manual. Federal Emergency Management Agency, Washington, DC.

Hela, D G, Lambropoulou, D A, Konstantinou, I K, Albanis, T A, 2005. Environmenta monitoring and ecological risk assessment for pesticide contamination and effects in Lake Pamvotis, northwestern Greece. Environmental Toxicology and Chemistry: An International Journal 24 (6), 1548-1556.

Herold, M, Roberts, D, 2005. Spectral characteristics of asphalt road aging and deterioration: implications for remote-sensing applications. Appl. Opt. 44 (20), 4327-4334.

Highways England, 2016. Resilience of Geotechnical Assets on the Strategic Road Network to Severe Weather Events. Phase 2 - Final Report, Issue 3.

Highways England Climate adaptation risk assessment progress update - 2016available onlinehttps://assets.publishing.service.gov.uk/government/uploads/system/uploads/ attachment_data/file/596812/climate-adrep-highways-england.pdf2016

Hornbostel, K, Larsen, C K, Geiker, R M, 2013. Relationship between concrete resistivity and corrosion rate - a literature review. Cem. Concr. Compos. 39, 60-72 ISSN 0958-9465. https://doi.org/10.1016/j.cemconcomp.2013.03.019.

Hosseini, S, Barker, K, Ramirez-Marquez, J E, 2016. A review of definitions and measures of system resilience. Reliability Engineering \& System Safety 145, 47-61.

Hoult, N, Dutton, M, Hoag, A, Take, W, 2016. Measuring crack movement in reinforced concrete using digital image correlation: overview and application to shear slip measurements. Proc. IEEE 104 (8), 1561-1574.

IAEA: International Atomic Energy Agency, 2018. Training Guidelines in Non-destructive Testing Techniques. TRAINING COURSE SERIES, Vienna.

Im, S, Hurlebaus, S, Kang, Y, 2013. Summary review of GPS technology for structural health monitoring. J. Struct. Eng. 139 (10), 1653-1664.

International Transport Forum, 2018. Policies to Extend the Life of Road Assets. (Paris)

Iyer, S, Sinha, S, Schokker, A, 2005. Ultrasonic C-scan imaging of post-tensioned concrete bridge structures for detection of corrosion and voids. Computer-Aided Civil and Infrastructure Engineering 20 (2), 79-94.

Jaishi, B, Ren, W X, 2005. Structural finite element model updating using ambient vibration test results. J. Struct. Eng. 131 (4), 617-628. 
Jaishi, B, Ren, W X, 2006. Damage detection by finite element model updating using modal flexibility residual. J. Sound Vib. 290 (1-2), 369-387.

Jáuregui, D, White, K, Pate, J, Woodward, C, 2005. Documentation of bridge inspection projects using virtual reality approach. J. Infrastruct. Syst. 11 (3), 172-179.

Jian, J, Ryu, D, Costelloe, J F, Su, C H, 2017. Towards hydrological model calibration using river level measurements. Journal of Hydrology: Regional Studies 10, 95-109.

Joshi, S, Harle, S M, 2017. Linear variable differential transducer (LVDT) \& its application in civil engineering. Int. J. Transp. Eng. Technol 3, 62-66.

Kaiser, M S, Lwin, K T, Mahmud, M, Hajializadeh, D, Chaipimonplin, T, Sarhan, A, Hossain, M A, 2017. Advances in crowd analysis for urban applications through urban event detection. IEEE Trans. Intell. Transp. Syst. 19 (10), 3092-3112.

Kappos, A J, 2016. An overview of the development of the hybrid method for seismic vulnerability assessment of buildings. Struct. Infrastruct. Eng. 12 (12), 1573-1584.

Karabinis, A I, Rousakis, T C, 2010. Evaluation of RVS method for pre-seismic assessment of structures utilizing post-earthquake damage investigations. In: Mazzolani, F M (Ed.), Urban Habitat Constructions under Catastrophic Events: Proceedings of the COST C26 Action Final Conference. CRC Press (2010 Aug 27).

Karayannis, C G, Chalioris, C E, Angeli, G M, Papadopoulos, N A, Favvata, M J, Providakis, C P, 2016. Experimental damage evaluation of reinforced concrete steel bars using piezoelectric sensors. Constr. Build. Mater. 105, 227-244.

Katunin, A, Dragan, K, Dziendzikowski, M, 2015. Damage identification in aircraft composite structures: a case study using various non-destructive testing techniques. Compos. Struct. 127, 1-9.

Kaundinya, I, Nisancioglu, S, Kammerer, H, Oliva, R, 2016. All-hazard guide for transport infrastructure. In: 6th Transport Research Arena. Transportation Research Procedia, 14. pp. 1325-1334.

Khaloo, A, Lattanzi, D, Cunningham, K, Dell'Andrea, R, Riley, M, 2018. Unmanned aeria vehicle inspection of the Placer River Trail Bridge through image-based 3D modelling. Struct. Infrastruct. Eng. 14 (1), 124-136.

Khan, F, Bartoli, I, 2015. Detection of delamination in concrete slabs combining infrared thermography and impact echo techniques: a comparative experimental study. In: Proceedings Volume 9437, Structural Health Monitoring and Inspection of Advanced Materials, Aerospace, and Civil Infrastructure, 2015. p. 94370I (2015).

Kiani, J, Camp, C, Pezeshk, S, 2019. On the application of machine learning techniques to derive seismic fragility curves. Comput. Struct. 218, 108-122.

Kim, E J, Park, H C, Ham, S W, Kho, S Y, Kim, D K, 2019. Extracting vehicle trajectorie using unmanned aerial vehicles in congested traffic conditions. J. Adv. Transp. 2019

Ko, J, Ni, Y, 2005. Technology developments in structural health monitoring of large-scale bridges. Eng. Struct. 27 (12), 1715-1725.

Kohrangi, M, Bazzurro, P, Vamvatsikos, D, 2016. Vector and scalar IMs in structura response estimation, part I: hazard analysis. Earthquake Spectra 32 (3), 1507-1524.

Kundu, T, 2014. Ultrasonic and electromagnetic waves for nondestructive evaluation and structural health monitoring. Procedia Engineering 86, 395-405.

Lamb, R, Aspinall, W, Odbert, H, Wagener, T, 2017. Vulnerability of bridges to scour: insights from an international expert elicitation workshop. Nat. Hazards Earth Syst. Sci. 17 (8), 1393-1409.

Lambert, P, Van Nguyen, C, Mangat, P S, O'Flaherty, F J, Jones, G, 2015. Dual function carbon fibre fabric strengthening and impressed current cathodic protection (ICCP) anode for reinforced concrete structures. Mater. Struct. 48 (7), 2157-2167.

Lee, C., Take, W.A., Hoult, N.A., (2012). Optimum accuracy of two-dimensional strain measure-ments using digital image correlation. J. Comp. Civ. Eng. 26 (6), 795-803.http://dx.doi.org/10.1061/(ASCE)CP.1943-5487.0000182.

Li, Y, Wang, H, Zhu, W, Li, S, Liu, J, 2015. Structural stability monitoring of a physical model test on an underground cavern group during deep excavations using FBG sensors. Sensors 15 (9), 21696-21709.

Li, M, Faghri, A, Ozden, A, Yue, Y, 2017. Economic feasibility study for pavement monitoring using synthetic aperture radar-based satellite remote sensing: cost-benefit analysis. Transp. Res. Rec. 2645 (1), 1-11.

Liang, Y, Wu, D, Liu, G, Li, Y, Gao, C, Ma, Z J, Wu, W, 2016. Big data-enabled multiscale serviceability analysis for aging bridges 2 . Digital Communications and Networks 2 (3), 97-107.

Linkov, I, Trump, B D, 2019. The Science and Practice of Resilience. Springer Internationa Publishing.

Linkov, I, Bridges, T, Creutzig, F, Decker, J, Fox-Lent, C, Kröger, W, et al., 2014. Changing the resilience paradigm. Nat. Clim. Chang. 4 (6), 407.

Linkov, I, Fox-Lent, C, Read, L, Allen, C R, Arnott, J C, Bellini, E, Coaffee, J, Florin, M V, Hatfield, K, Hyde, I, Hynes, W, Jovanovic, A, Ksperson, R, Katzenberger, J, Keys, P W, Lambert, J, Moss, R, Murdoch, P, Palma-Oliviera, J, Pulwarty, R, Sands, D, Thonas, E A, Tye, R M, Wood, D, 2018. Tiered approach to resilience assessment. Risk Anal. 38 (9), 1772-1780

Liu, H J, Love, P E, Sing, M C, Niu, B, Zhao, J, 2019. Conceptual framework of life-cycle performance measurement: ensuring the resilience of transport infrastructure assets. Transp. Res. Part D: Transp. Environ. 77, 615-626.

Lloyd's Register foundation, (2014). Foresight review of big data: towards data-centric en gineering, report series: no.2014.2https://www.lrfoundation.org.uk/en/publications foresight-review-of-big-data/ (accessed online, March 2020).

Lloyd's Register foundation, (2015). Foresight review of resilience engineering: designing for the expected and unexpected, report series: no. 2015.2, available online https: //www.lrfoundation.org.uk/en/publications/resilience-engineering/ (accessed online March 2020).

Loucks, D P, Van Beek, E, 2017. Water Resource Systems Planning and Management: An Introduction to Methods, Models, and Applications. Springer.

Love, P E, Liu, J, Matthews, J, Sing, C P, Smith, J, 2015. Future proofing PPPs: life-cycle performance measurement and building information modelling. Autom. Constr. 56, $26-35$.
Luo, R C, 1996. Sensor technologies and microsensor issues for mechatronics systems. IEEE/ASME Transactions on Mechatronics 1 (1), 39-49.

Lustenberger, P, Schumacher, F, Spada, M, Burgherr, P, Stojadinovic, B, 2019. Assessing the performance of the European natural gas network for selected supply disruption scenarios using open-source information. Energies 12 (24), 4685.

Macdonald, D, 1990. Some advantages and pitfalls of electrochemical impedance spectroscopy. Corrosion 46 (3), 229-242.

Mangalathu, S, Jeon, J S, 2019. Stripe-based fragility analysis of multispan concrete bridge classes using machine learning techniques. Earthquake Engineering \& Structural Dynamics 48 (11), 1238-1255.

Marchese, D, Jin, A, Fox-Lent, C, Linkov, I, 2020. Resilience for smart water systems. J. Water Resour. Plan. Manag. 146 (1), 02519002.

Markolf, S A, Chester, M V, Eisenberg, D A, Iwaniec, D M, Davidson, C I, Zimmerman, $\mathrm{R}$, Chang, H, 2018. Interdependent infrastructure as linked social, ecological, and technological systems (SETSs) to address lock-in and enhance resilience. Earth's Future 6 (12), 1638-1659.

Mattsson, L G, Jenelius, E, 2015. Vulnerability and resilience of transport systems-a discussion of recent research. Transp. Res. A Policy Pract. 81, 16-34.

McCann, D, Forde, M, 2001. Review of NDT methods in the assessment of concrete and masonry structures. NDT \& E International 34 (2), 71-84.

McCormick, N, Lord, J, 2010. Digital image correlation. Mater. Today 13 (12), 52-54 2010. (ISSN 1369-7021)

Meo, M, 2014. Acoustic emission sensors for assessing and monitoring civil infrastructures. In: Wang, M L, Lynch, J P, Sohn, H (Eds.), Woodhead Publishing Series in Electronic and Optical Materials, Sensor Technologies for Civil Infrastructures, Volume 55. Woodhead Publishing, pp. 159-178 (ISBN 9780857094322).

Miller, P E, Mills, J P, Barr, S L, Birkinshaw, S J, Hardy, A J, Parkin, G, Hall, S J, 2011. A remote sensing approach for landslide hazard assessment on engineered slopes. IEEE Trans. Geosci. Remote Sens. 50 (4), 1048-1056.

Mitoulis, S, Argyroudis, S, Lamb, R, 2019. Risk and Resilience of Bridgeworks Exposed to Hydraulic Hazards, IABSE2019-New York, September 4-6.

Moreno-Gomez, A, Perez-Ramirez, C A, Dominguez-Gonzalez, A, Valtierra-Rodriguez, M, Chavez-Alegria, O, Amezquita-Sanchez, J P, 2018. Sensors used in structural health monitoring. Archives of Computational Methods in Engineering 25 (4), 901-918.

Morris, W, Vico, A, Vazquez, M, de Sanchez, S R, 2002. Corrosion of reinforcing steel evaluated by means of concrete resistivity measurements. Corros. Sci. 44 (1), 81-99 ISSN 0010-938X. https://doi.org/10.1016/S0010-938X(01)00033-6.

Mottershead, J E, Link, M, Friswell, M I, 2011. The sensitivity method in finite element model updating: a tutorial. Mech. Syst. Signal Process. 25 (7), 2275-2296.

Murphy, R R, Duncan, B A, Collins, T, Kendrick, J, Lohman, P, Palmer, T, Sanborn, F, 2016. Use of a small unmanned aerial system for the SR-530 mudslide incident near Oso, Washington. Journal of field Robotics 33 (4), 476-488.

Mutlib, N, Baharom, S, El-Shafie, A, Nuawi, M, 2015. Ultrasonic health monitoring in structural engineering: buildings and bridges. Struct. Control. Health Monit. 23 (3), 409-422.

Nair, A, Cai, C, 2010. Acoustic emission monitoring of bridges: review and case studies. Eng. Struct. 32 (6), 1704-1714.

Nasr, A, Kjellström, E, Björnsson, I, Honfi, D, Ivanov, O L, Johansson, J, 2019. Bridges in a changing climate: a study of the potential impacts of climate change on bridges and their possible adaptations. Struct. Infrastruct. Eng. 1-12.

NCHRP, 2018. Resilience in Transportation Planning, Engineering, Management, Policy, and Administration. The National Academies Press, Washington, DC. doi:10.17226/ 25166.

Neftci, E O, Mostafa, H, Zenke, F, 2019. Surrogate gradient learning in spiking neural networks: bringing the power of gradient-based optimization to spiking neural networks. IEEE Signal Process. Mag. 36 (6), 51-63.

Ngamkhanong, C, Kaewunruen, S, Costa, B, 2018. State-of-the-art review of railway track resilience monitoring. Infrastructures 3 (1), 3

Nocera, F, Gardoni, P, Cimellaro, G P, 2019. Time-dependent probability of exceeding a target level of recovery. ASCE-ASME Journal of Risk and Uncertainty in Engineering Systems, Part A: Civil Engineering 5 (4), 4019013.

Ohtsu, M, 2015. Acoustic emission and related non-destructive evaluation techniques in the fracture mechanics of concrete. In: Woodhead Publishing Series in Civil and Structural Engineering: Number 57. Elsevier.

Omar, T, Nehdi, M L, 2017. Remote sensing of concrete bridge decks using unmanned aerial vehicle infrared thermography. Autom. Constr. 83, 360-371.

Ou, Y W, Dertimanis, V K, Chatzi, E N, 2017. Operational damage localization of wind turbine blades. In: International Conference on Experimental Vibration Analysis for Civil Engineering Structures. Springer, Cham, pp. 261-272 July.

Ouyang, M, Wang, Z, 2015. Resilience assessment of interdependent infrastructure systems: with a focus on joint restoration modeling and analysis. Reliab. Eng. Syst. Saf. 141, 74-82.

Ozevin, D, Greve, D, Oppenheim, I, Pessiki, S, 2006. Resonant capacitive MEMS acoustic emission transducers. Smart Mater. Struct. 15 (6), 1863-1871.

Padgett, J E, DesRoches, R, 2007. Bridge functionality relationships for improved seismic risk assessment of transportation networks. Earthquake Spectra 23 (1), 115-130.

Palacz, M, 2018. Spectral methods for modelling of wave propagation in structures in terms of damage detection-a review. Appl. Sci. 8 (7), 1124.

Pan, Y, Zhang, X, Cervone, G, Yang, L, 2018. Detection of asphalt pavement potholes and cracks based on the unmanned aerial vehicle multispectral imagery. IEEE Journal of Selected Topics in Applied Earth Observations and Remote Sensing 11 (10), 3701-3712.

Pant, R, Thacker, S, Hall, J W, Alderson, D, Barr, S, 2018. Critical infrastructure impact assessment due to flood exposure. Journal of Flood Risk Management 11, 22-33. 
Park, H, Lee, H, Adeli, H, Lee, I, 2007. A new approach for health monitoring of structures: terrestrial laser scanning. Computer-Aided Civil and Infrastructure Engineering 22 (1), 19-30.

Park, H, Lee, H, Choi, S, Kim, Y, 2013. A practical monitoring system for the structural safety of mega-trusses using wireless vibrating wire strain gauges. Sensors 13 (12), 17346-17361.

Park, H, Lee, H, Choi, S, Kim, Y, 2013. A practical monitoring system for the structural safety of mega-trusses using wireless vibrating wire strain gauges. Sensors 13 (12), 17346-17361.

Park, H, Shin, Y, Choi, S, Kim, Y, 2013. An integrative structural health monitoring system for the local/global responses of a large-scale irregular building under construction. Sensors 13 (7), 9085-9103.

Park, J, Sim, S, Jung, H, 2013. Displacement estimation using multimetric data fusion. IEEE/ASME Transactions on Mechatronics 18 (6), 1675-1682.

Pau, A, Achillopoulou, D V, Vestroni, F, 2016. Scattering of guided shear waves in plates with discontinuities. NDT \& E International 84, 67-75.

Pavlopoulou, S, Staszewski, W J, Soutis, C, 2013. Evaluation of instantaneous characteristics of guided ultrasonic waves for structural quality and health monitoring. Struct. Control. Health Monit. 20 (6), 937-955.

Pedram, M, Esfandiari, A, Khedmati, M R, 2016. Finite element model updating using strain-based power spectral density for damage detection. Struct. Control. Health Monit. 23 (11), 1314-1333.

Picozzi, M, 2012. An attempt of real-time structural response assessment by an interferometric approach: a tailor-made earthquake early warning for buildings. Soil Dyn. Earthq. Eng. 38, 109-118.

Polyfytos bridge Retrieved fromhttp://www.infrastructuresilience.com/lake-polyfytosbridge 2020

Porter, K, 2015. Beginner's guide to fragility, vulnerability, and risk. In: Beer, M, Kougioumtzoglou, I A, Patelli, E, Au, S-K (Eds.), Encyclopedia of Earthquake Engineering. Springer-Verlag, Berlin Heidelberg (ISBN 978-3-642-35345-1).

Pregnolato, M, Ford, A, Wilkinson, S M, Dawson, R J, 2017. The impact of flooding on road transport: a depth-disruption function. Transp. Res. D 55, 67-81.

Prendergast, L J, Gavin, K, 2014. A review of bridge scour monitoring techniques. J. Rock Mech. Geotech. Eng. 6, 138-149.

Pritchard, O, Bhreasail, A N, Campbell, G, Carluccio, S, Willis, M, Codd, J, 2018. Practical remote survey applications for improved geotechnical asset management on England's strategic road network. In: Proc 7th Transport Research Arena TRA 2018, Vienna, Austria.

Randall, T, 2011. Construction engineering requirements for integrating laser scanning technology and building information modeling. J. Constr. Eng. Manag. 137 (10), 797-805

Reddy, R R, Komeda, K, Okamoto, Y, Lebrasseur, E, Higo, A, Mita, Y, 2019. A zero-power sensing MEMS shock sensor with a latch-reset mechanism for multi-threshold events monitoring. Sensors Actuators A Phys. 295, 1-10.

Reeves, S., Winter, M., Leal, D., and Hewitt, A. 2019. Roads: an industry guide to enhancing resilience. Resilience primer. TRL and resilience shift, UK. Available online: https://www.resilienceshift.org/publication/primer-roads/.

Renne, J, Wolshon, B, Murray-Tuite, P, Pande, A, 2019. Emergence of resilience as a framework for state Departments of Transportation (DOTs) in the United States. Transp. Res. Part D: Transp. Environ.. doi:10.1016/j.trd.2019.11.007.

Ribeiro, D V, Abrantes, J C C, 2016. Application of electrochemical impedance spectroscopy (EIS) to monitor the corrosion of reinforced concrete: a new approach. Constr. Build. Mater. 111, 98-104 ISSN 0950-0618. https://doi.org/10.1016/j. conbuildmat.2016.02.047.

Riveiro, B, González-Jorge, H, Varela, M, Jauregui, D, 2013. Validation of terrestrial laser scanning and photogrammetry techniques for the measurement of vertical underclearance and beam geometry in structural inspection of bridges. Measurement 46 (1), 784-794.

Romero-Lankao, Patricia, Bruns, Antje, Wiegleb, Viviana, 2018. From risk to WEF security in the city: the influence of interdependent infrastructural systems. Environ. Sci. Pol. 90, 213-222.

Rose, J L, 2004. Ultrasonic guided waves in structural health monitoring. In: Key Engineering Materials, 270. Trans Tech Publications, pp. 14-21.

Roshandeh, A M, Poormirzaee, R, Ansari, F S, 2014. Systematic data management for real-time bridge health monitoring using layered big data and cloud computing. International Journal of Innovation and Scientific Research 2 (1), 29-39.

Saboonchi, H, Ozevin, D, Kabir, M, 2016. MEMS sensor fusion: acoustic emission and strain. Sensors Actuators A Phys. 247, 566-578.

Sachs, J D, Schmidt-Traub, G, Mazzucato, M, Messner, D, Nakicenovic, N, Rockström, J, 2019. Six transformations to achieve the sustainable development goals. Nature Sustainability 2 (9), 805-814.

Salvo, G, Caruso, L, Scordo, A, Guido, G, Vitale, A, 2017. Traffic data acquirement by unmanned aerial vehicle. European journal of remote sensing 50 (1), 343-351.

Sarkodie, S A, Strezov, V, 2019. Economic, social and governance adaptation readiness for mitigation of climate change vulnerability: evidence from 192 countries. Sci. Total Environ. 656, 150-164.

Schweikert, A, Espinet, X, Goldstein, S, Chinowsky, P, 2015. Resilience versus risk: assessing cost of climate change adaptation to California's transportation system and the City of Sacramento, California. Transp. Res. Rec. 2532 (1), 13-20.

Scott, M, Rezaizadeh, A, Delahaza, A, Santos, C, Moore, M, Graybeal, B, Washer, G, 2003. A comparison of non-destructive evaluation methods for bridge deck assessment. NDT \& E International 36 (4), 245-255.

Seraj, F, Meratnia, N, Havinga, P J, 2017. An aggregation and visualization technique for crowd-sourced continuous monitoring of transport infrastructures. In: 2017 IEEE
International Conference on Pervasive Computing and Communications Workshops (PerCom Workshops). IEEE, pp. 219-224 March.

SHM: Structural Health Monitoring, 2013. A Major Qualifying Project Report Submitted to the Faculty of the WORCESTER POLYTECHNIC INSTITUTE.

Simoen, E, De Roeck, G, Lombaert, G, 2015. Dealing with uncertainty in model updating for damage assessment: a review. Mech. Syst. Signal Process. 56, 123-149.

Simpson, T, Dertimanis, V, Papadimitriou, C, Chatzi, E, 2019. On the potential of dynamic sub-structuring methods for model updating. Struct. Health Monit. 2019.

Skarżyński, Ł, Suchorzewski, J, 2018. Mechanical and fracture properties of concrete reinforced with recycled and industrial steel fibers using Digital Image Correlation technique and X-ray micro computed tomography. Constr. Build. Mater. 183, 283-299.

Snieder, R, 2006. Extracting the building response using seismic interferometry: theory and application to the Millikan library in Pasadena, California. Bull. Seismol. Soc. Am. 96 (2), 586-598.

Sohn, H, Dutta, D, Yang, J Y, Park, H J, DeSimio, M, Olson, S, Swenson, E, 2011. Delamination detection in composites through guided wave field image processing. Compos. Sci. Technol. 71 (9), 1250-1256.

Soman, R, Majewska, K, Mieloszyk, M, Ostachowicz, W, 2018. Damage assessment in composite beam using infrared thermography, optical sensors, and terahertz technique. Journal of Nondestructive Evaluation, Diagnostics and Prognostics of Engineering Systems 1 (3).

Song, T, Cai, J, Chahine, T, Li, L, 2017. Towards smart cities by internet of things (IoT)-a silent revolution in China. J. Knowl. Econ. 1-17.

Srinivasan, S, Muck, A J, Chou, P W, 2010. Real-time slope and wall monitoring and reporting using 3-D MEMS-based, in-place instrumentation system. In: GeoFlorida 2010: Advances in Analysis, Modeling \& Design. pp. 1172-1181.

St Leger, J, Anderson, M, Babin, S, 2014. Smart structural monitoring of long-span Bridges. In: Istanbul Bridge Conference August.

Stamos, I, Mitsakis, E, Grau, J M S, 2015. Roadmaps for adaptation measures of transportation to climate change. Transp. Res. Rec. 2532 (1), 1-12.

Talakokula, V, Bhalla, S, Gupta, A, 2013. Corrosion assessment of reinforced concrete structures based on equivalent structural parameters using electro-mechanical impedance technique. J. Intell. Mater. Syst. Struct. 25 (4), 484-500.

Tarussov, A, Vandry, M, De La Haza, A, 2013. Condition assessment of concrete structure using a new analysis method: ground-penetrating radar computer-assisted visual interpretation. Constr. Build. Mater. 38, 1246-1254.

Teughels, A, Maeck, J, De Roeck, G, 2002. Damage assessment by FE model updating using damage functions. Comput. Struct. 80 (25), 1869-1879.

Todorovska, M, 2009. Seismic interferometry of a soil-structure interaction model with coupled horizontal and rocking response. Bull. Seismol. Soc. Am. 99 (2A), 611-625.

Tokognon, C A, Gao, B, Tian, G Y, Yan, Y, 2017. Structural health monitoring framework based on internet of things: a survey. IEEE Internet Things J. 4 (3), 619-635.

Torbol, M, Gomez, H, Feng, M, 2013. Fragility analysis of highway bridges based on long-term monitoring data. Computer-Aided Civil and Infrastructure Engineering 28 (3), 178-192.

UNDRR, 2011. Climate Change Adaptation and Disaster Risk Reduction in Europe: A Review of Risk Governance. United Nations Office for Disaster Risk Reduction Regional Office for Europe, Council of Europe, European and Mediterranean Major Hazards Agreement.

UNISDR, 2009. Terminology on disaster risk reduction. In: United Nations International Strategy for Disaster Reduction, Geneva, Switzerland. http://unisdr.org/eng/library/ lib-terminology-eng.htm.

United Nations General Assembly Transforming our world: the 2030 agenda for sustainable development, United Nations, New Yorkhttp://www.un.org/ga/search/view doc.asp?symbol =A/RES/70/1\&Lang = E201519 May 2020

Usamentiaga, R, Venegas, P, Guerediaga, J, Vega, L, Molleda, J, Bulnes, F, 2014. Infrared thermography for temperature measurement and non-destructive testing. Sensors 14 (7), 12305-12348.

Valkaniotis, S, Papathanassiou, G, Ganas, A, 2018. Mapping an earthquake-induced landslide based on UAV imagery; case study of the 2015 Okeanos landslide, Lefkada, Greece. Eng. Geol. 245, 141-152.

Vamvakeridou-Lyroudia, L S, Chen, A S, Khoury, M, Gibson, M J, Kostaridis, A, Stewart, D, Savic, D A, 2020. Assessing and visualising hazard impacts to enhance the resilience of critical infrastructures to urban flooding. Sci. Total Environ. 707, 136078.

Verma, S, Bhadauria, S, Akhtar, S, 2013. Review of nondestructive testing methods for condition monitoring of concrete structures. Journal of Construction Engineering 2013, 1-11.

Wang, Y, Zhang, T, 2013. Finite element model updating using estimation of distribution algorithm. In: SHMII-6 2013: The 6th International Conference on Structural Health Monitoring of Intelligent Infrastructure, 2013-12-09 - 2013-12-09, Hong Kong, China.

Wang, W, Mottershead, J E, Ihle, A, Siebert, T, Schubach, H R, 2011. Finite element model updating from full-field vibration measurement using digital image correlation. J. Sound Vib. 330 (8), 1599-1620.

Wang, Y, Zhu, X, Hao, H, Ou, J, 2011. Spectral element model updating for damage identification using clonal selection algorithm. Adv. Struct. Eng. 14 (5), 837-856.

Wang, W, Yang, N, Zhang, Y, Wang, F, Cao, T, Eklund, P, 2016. A review of road extraction from remote sensing images. Journal of Traffic and Transportation Engineering (English edition) 3 (3), 271-282.

Wang, Y, Zhang, D, Liu, Y, Dai, B, Lee, L H, 2019. Enhancing transportation systems via deep learning: a survey. Transportation research part C: emerging technologies 99, 144-163. 
Webb, G T, Vardanega, P J, Middleton, C R, 2015. Categories of SHM deployments: technologies and capabilities. J. Bridg. Eng. 20 (11), 04014118.

Weng, S, Xia, Y, Xu, Y L, Zhu, H P, 2011. Substructure based approach to finite element model updating. Comput. Struct. 89 (9-10), 772-782.

Whyte, J, Chen, L, Gamble, C, Genes, C, Pierce, K, Fitzgerald, J, Coca, D, Mayfield, M, Babovic, F, Pedro, A, Shah, N, 2019. Analysing Systems Interdependencies Using a Digital Twin, 2018/19 General Project Funded by CDBB, Final Report.

Winter, M G, 2014. A strategic approach to landslide risk reduction. International Journal of Landslide and Environment 2 (1), 14-23.

J. Woetzel D. Pinner H. Samandari H. Engel M. Krishnan B. Boland C. Powis Climate risk and response: physical hazards and socioeconomic impactsAvailable onlineMcKinsey Global Institutehttps://www.mckinsey.com/business-functions/sustainability/ our-insights/climate-risk-and-response-physical-hazards-and-socioeconomicimpacts 2020

Wolf, R E, Bouali, E H, Oommen, T, Dobson, R, Vitton, S, Brooks, C, Lautala, P, 2015 Final Report: Sustainable Geotechnical Asset Management along the Transportation Infrastructure Environment Using Remote Sensing. Michigan Technological University, USDOT Cooperative Agreement No. RITARS-14-H-MTU.

World Economic Forum The Europe 2020 competitiveness report: building a more competitive Europe[online] Geneva, Available athttp://www3.weforum.org/docs/WEF Europe2020_CompetitivenessReport_2014.pdf20145 October 2019

Woschitz, H, Macheiner, K, 2007. Static and kinematic testing of tiltmeters: facilities and results. Vermessung \& Geoinformation 2, 134-142.

Wu, S T, Mo, S C, Wu, B S, 2008. An LVDT-based self-actuating displacement transducer. Sensors Actuators A Phys. 141 (2), 558-564.

Wu, J, Li, Y, Li, N, Shi, P, 2018. Development of an asset value map for disaster risk assessment in China by spatial disaggregation using ancillary remote sensing data. Risk Anal. 38 (1), 17-30.

Xian, S, Yin, J, Lin, N, Oppenheimer, M, 2018. Influence of risk factors and past events on flood resilience in coastal megacities: comparative analysis of NYC and Shanghai. Sci. Total Environ. 610, 1251-1261.

$\mathrm{Xu}, \mathrm{Y}, 2$ 2012. Structural Health Monitoring of Long-Span Suspension Bridges. CRC Press, London and New York.

Xu, B, Giurgiutiu, V, Yu, L, 2009. Lamb waves decomposition and mode identification using matching pursuit method. In: Sensors and Smart Structures Technologies for Civil, Mechanical, and Aerospace Systems 2009, 7292. International Society for Optics and Photonics, p. 72920I March.

Yan, W, Chen, W, 2010. Structural health monitoring using high-frequency electromechanical impedance signatures. Advances in Civil Engineering 2010, 1-11.

Yang, D Y, Frangopol, D M, 2018. Bridging the gap between sustainability and resilience of civil infrastructure using lifetime resilience. In: Gardoni, P (Ed.), Chapter 23 in Routledge Handbook of Sustainable and Resilient Infrastructure. Routledge, pp. 419-442.

Yang, D Y, Frangopol, D M, 2019. Life-cycle management of deteriorating civil infrastructure considering resilience to lifetime hazards: a general approach based on renewal-reward processes. Reliability Engineering \& System Safety 183, 197-212.

Ye, H, Tian, Y, Jin, N, Jin, X, Fu, C, 2013. Influence of cracking on chloride diffusivity and moisture influential depth in concrete subjected to simulated environmental conditions. Constr. Build. Mater. 47, 66-79.

Ye, X, Su, Y, Han, J, 2014. Structural health monitoring of civil infrastructure using optical fiber sensing technology: a comprehensive review. Sci. World J. 2014, 1-11.

Yi, T H, Li, H N, Zhang, X D, 2012. A modified monkey algorithm for optimal sensor placement in structural health monitoring. Smart Mater. Struct. 21 (10), 105033.

Yi, T H, Li, H N, Wang, C W, 2016. Multiaxial sensor placement optimization in structural health monitoring using distributed wolf algorithm. Struct. Control. Health Monit. 23 (4), 719-734.

Yu, H, Caseres, L, 2012. An embedded multi-parameter corrosion sensor for reinforced concrete structures. Mater. Corros. 1011-1016.

I. Zachariadis Investment in infrastructure in the EU: gaps, challenges, and opportunities[online]. Available atEPRS| European Parliamentary Research Servicehttp://www. iberglobal.com/files/2018-2/infrastructure_eu.pdf20185 October 2019

Zekkos, D, Manousakis, J, Greenwood, W, Lynch, J, 2016. Immediate UAV-enabled infrastructure reconnaissance following recent natural disasters: Case histories from Greece. In: Proc: 1st International Conference on Natural Hazards and Infrastructure (ICONHIC).

Zhang, Q, Zhao, J, 2013. Determination of mechanical properties and full-field strain measurements of rock material under dynamic loads. Int. J. Rock Mech. Min. Sci. 60, 423-439.

Zhang, T, Biswal, S, Wang, Y, 2019. SHMnet: condition assessment of bolted connection with beyond human-level performance. Struct. Health Monit. (1475921719881237).

Zhu, B, Frangopol, D M, 2012. Reliability, redundancy and risk as performance indicators of structural systems during their life-cycle. Eng. Struct. 41, 34-49.

Zhu, H, Shi, B, Zhang, C, 2017. FBG-based monitoring of geohazards: current status and trends. Sensors 17 (3), 452.

Zou, Y, Kiviniemi, A, Jones, S W, 2017. A review of risk management through BIM and BIM-related technologies. Saf. Sci. 97, 88-98.

Zscheischler, J, Westra, S, Van Den Hurk, B J, Seneviratne, S I, Ward, P J, Pitman, A AghaKouchak, A, Bresch, D N, Leonard, M, Wahl, T, Zhang, X, 2018. Future climate risk from compound events. Nat. Clim. Chang. 8 (6), 469-477. 